Revue des patrimoines

25 | 2014

Le patrimoine de la Grande Guerre

\title{
Les monuments aux morts de la Guerre de 14-18 en Guadeloupe avant 1945
}

Séverine Laborie

\section{OpenEdition}

1 Journals

\section{Electronic version}

URL: http://journals.openedition.org/insitu/11721

DOI: 10.4000/insitu. 11721

ISSN: 1630-7305

\section{Publisher}

Ministère de la Culture

\section{Electronic reference}

Séverine Laborie, "Les monuments aux morts de la Guerre de 14-18 en Guadeloupe avant 1945 », In Situ [Online], 25 | 2014, Online since 16 January 2015, connection on 26 June 2020. URL : http:// journals.openedition.org/insitu/11721; DOI : https://doi.org/10.4000/insitu.11721

This text was automatically generated on 26 June 2020 .

\section{(c) (i) (9)}

In Situ Revues des patrimoines est mis à disposition selon les termes de la licence Creative Commons Attribution - Pas d'Utilisation Commerciale - Pas de Modification 4.0 International. 


\title{
Les monuments aux morts de la Guerre de 14-18 en Guadeloupe avant 1945
}

\author{
Séverine Laborie
}

L'auteur exprime ses remerciements aux archives départementales de la Guadeloupe, ainsi qu'à M. Camille Treber.

1 La constitution d'un dossier de protection portant sur le monument aux morts de la ville des Abymes en Guadeloupe en 2013, de même que la célébration du centenaire de la Grande Guerre, ont été l'occasion pour le service des Monuments historiques de la direction des Affaires culturelles de Guadeloupe de se pencher sur l'histoire et l'analyse de ces édifices d'un genre particulier. Le mémoire de maîtrise de Philippe Erbs ${ }^{12}$ dirigé par Danielle Bégot en 2003 a constitué un apport essentiel à notre connaissance, en particulier pour les dates d'inauguration et le montant des travaux d'édification, quand ils étaient connus. En effet, il faut souligner ici les limites de cette étude, liées au manque de temps à consacrer à la recherche en archives, lesquelles sont d'ailleurs fort lacunaires en ce qui concerne les monuments aux morts de Guadeloupe. Les archives des communes, dans lesquelles on aurait espéré trouver les contrats de commandes, ont en partie disparu, ou n'ont pas été encore identifiées. Les archives départementales réservent sans doute encore quelques surprises, mais les archives nationales ne conservent aucune trace des commandes guadeloupéennes. Ce manque de sources doit donc conduire à la prudence. L'approche privilégiée a plutôt été celle de l'historien de l'art, l'analyse stylistique des œuvres permettant d'apporter des précisions utiles, tant sur les sculptures fabriquées en série que sur les créations originales, et d'alimenter une réflexion sur l'opportunité de proposer des protections au titre des monuments historiques. 


\section{La participation des Guadeloupéens à la guerre}

\section{Le désir d'assimilation et l'« impôt du sang »}

2 Avec son vaste empire colonial étendu sur quatre continents grâce auquel elle fait plus que doubler sa population ${ }^{3}$, la France est, à la veille de la guerre, une des plus grandes puissances mondiales. Mais la situation politique des "quatre vieilles", comme sont parfois désignées la Guadeloupe, la Martinique, la Guyane et la Réunion, n'est pas comparable à celle des autres pays de l'empire colonial français. Rattachés à la France depuis plus longtemps que certaines régions métropolitaines, ces territoires ultramarins sont imprégnés par l'idéal républicain depuis la Révolution et la première abolition de l'esclavage ${ }^{4}$. La classe politique antillaise fait consensus autour du projet politique assimilationniste qui est à l'origine de l'engagement de soldats antilloguyanais dans la guerre.

\section{Anciennes colonies et citoyenneté}

3 La citoyenneté française a en effet été accordée une première fois aux nouveaux libres par la Convention, qui l'inscrit dans le décret d'abolition en ces termes: «La Convention nationale déclare abolir l'esclavage des Nègres dans toutes les colonies. En conséquence, elle décrète que les hommes, sans distinction de couleur, domiciliés dans les colonies, sont citoyens français et jouiront de tous les droits assurés par la Constitution. " Les Thermidoriens vont plus loin en instituant une nouvelle architecture institutionnelle assimilationniste dans la politique coloniale française et font voter la première loi constitutionnelle qui tend à transformer les vieilles colonies en départements le 5 fructidor an III (22 août 1795), disposant que les «colonies françaises sont parties intégrantes de la République et sont soumises à la même loi constitutionnelle ». La Constitution de l'an III apparait bien comme le point de départ de la politique d'assimilation à la française, ce que confirme le rapport préparatoire de Boissy d'Anglas devant la commission thermidorienne qui déclare ainsi «Que les colonies soient toujours françaises (...) ; qu'elles soient libres sans être indépendantes ; qu'elles fassent partie de notre république indivisible; (...) que leurs députés, appelés dans cette enceinte, y soient confondus avec ceux du peuple entier qu'ils seront chargés de représenter. »

4 C'est cette volonté "d'assimiler en tout les colonies aux autres parties de la République » qui devient plus tard la politique traditionnelle de la France à l'égard des Antilles. Mais la mise en œuvre de cette «première départementalisation " se heurte à des troubles persistants, alimentés par la crainte du rétablissement de l'esclavage. De fait, sous le Consulat et l'Empire, le rétablissement de l'assujettissement, du régime des lois spéciales et, en 1802, de l'esclavage en Guadeloupe, marquent une rupture avec la politique assimilationniste. Bien que la rébellion de Guadeloupe ${ }^{5}$ soit réprimée dans le sang, le rétablissement de l'ordre ancien est difficilement tenable dans la mesure où la décision des Anglais d'interdire la traite négrière isole la France de la Déclaration des droits de l'homme. Saint-Domingue, fleuron des îles à sucre françaises, entre en guerre contre l'autorité coloniale et proclame son indépendance le $1^{\mathrm{er}}$ janvier 1804 . Cet événement déstabilise l'économie esclavagiste de toute la Caraïbe et dès lors, l'Empire affaibli ne parvient pas à conserver ses possessions antillaises qui sont occupées par les Anglais de 1809 à 1815. À l'exemple des autres nations européennes, la France renonce 
officiellement à la traite négrière en 1815 , cependant un trafic illicite se maintient jusque dans les années 1830 avec la complaisance des autorités françaises ${ }^{6}$.

Dans ce contexte, une classe de « libres de couleur » instruite et consciente de ses droits bafoués se développe et multiplie les affrontements avec la société esclavagiste agonisante, tandis que des soulèvements d'esclaves se multiplient, en particulier en Martinique. En métropole, la voix des abolitionnistes, notamment celle de l'abbé Grégoire puis celle de Victor Schœlcher (fig. 1), font progresser le débat sans toutefois concrétiser l'abolition immédiate, qui n'est votée qu'à l'issue de la révolution de 1848 .

Figure 1

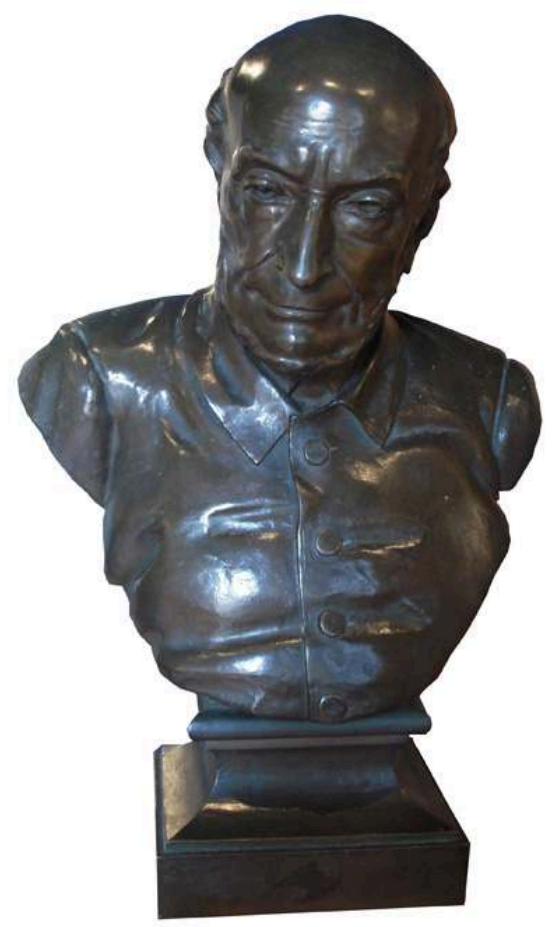

Buste de Victor Schœlcher, bronze. Musée Schœlcher, Pointe-à-Pitre.

(c) Conseil général de la Guadeloupe.

Outre l'abolition immédiate, la II $^{\mathrm{e}}$ République instaure aux Antilles une vie démocratique, fondée en droit sur le suffrage universel et une certaine assimilation institutionnelle entre les colonies et la métropole ${ }^{7}$. Schœlcher, dans un discours de 1848, se montre clairement assimilationniste : "purifiées de la servitude, les colonies sont désormais une partie intégrante de la Métropole; disons mieux, il n'y a plus de colonies, il n'y a que des Départements d'Outre-Mer régis par les mêmes lois que ceux du continent $»^{8}$.

7 Mais si les anciens esclaves sont devenus citoyens français, la question de l'application concrète des droits qui leurs sont reconnus par le décret de 1848 rencontre de nombreux obstacles, dressés en particulier par les grands propriétaires qui se ressaisissent en même temps que progresse la réaction anti-républicaine en métropole. Tous les volets de la République sociale sont bafoués et le droit à l'instruction est conditionné par l'obligation, pour les nouveaux libres, de rester attachés au sol des 
grandes habitations; quant à la liberté de la presse, elle est un leurre. De l'œuvre progressiste de Schœlcher ne reste que l'abolition de l'esclavage et le droit de vote.

8 Le Second Empire marque une nouvelle régression en matière de droits civils et politiques, et c'est seulement avec l'avènement de la III ${ }^{e}$ République que resurgissent les revendications d'assimilation, en arrière-plan desquelles se profile la départementalisation qui apparaît de plus en plus inéluctable pour régler le problème du statut des «quatre vieilles» colonies. Le conseil général de la Martinique, particulièrement actif sur ce sujet, en formule le vœu à plusieurs reprises, dès 1874 , puis en 1882, 1885, 1889.

La guerre offre à la classe politique antillaise une nouvelle occasion de faire entendre l'attente d'une évolution statutaire, cependant et malgré le sang versé, la question est de nouveau ajournée. Il faut attendre le rapport Leconte, établi en 1925, et la Deuxième Guerre mondiale pour que cette demande récurrente d'assimilation, portée par plusieurs générations d'hommes politiques martiniquais et guadeloupéens n'aboutisse enfin en 1945. En effet, après le sombre intermède vichyste qui avait rétabli la discrimination raciale, personne ne doutait que le moment était venu de réaliser cette assimilation et de la concrétiser par la départementalisation des « quatre vieilles ».

\section{La loi sur la conscription et « l'impôt du sang »}

10 C'est cette volonté de faire reconnaître les colonies « comme terres françaises, parties intégrantes de la République » qui pousse la classe politique antillaise, majoritairement assimilationniste, à réclamer une égalité de traitement avec la métropole au regard du service militaire.

11 Victor Schœlcher est à l'origine de ce combat pour l'application de la conscription militaire dans les anciennes colonies, dont il fait un pivot de son argumentation assimilationniste. Dans un article du journal Le Rappel du 12 juillet 1878, il réclame l'instauration du service militaire aux colonies, lequel doit permettre selon lui «la fusion des races et a le mérite d'enseigner l'égalité et de combattre l'esprit de caste et les maux qu'il engendre ». Dans Le Moniteur des Colonies du 13 juillet 1884, il écrit encore au sujet de la conscription: c'est "l'assimilation complète, absolue des Français d'Outre-Mer avec ceux de la Métropole». L'accorder constituerait selon lui le témoignage de la confiance de la Chambre «dans le patriotisme et les sentiments tout français de l'immense majorité des populations coloniales.» Il perçoit ainsi cet engagement réciproque comme le gage de la réussite de l'intégration des anciennes colonies à la nation.

12 Malgré le crédit porté à Schœlcher, les lois sur le service militaire de 1889 et de $1905^{9}$ n'intègrent pas les ultramarins. La préparation de la loi sur la conscription militaire du 7 août 1913 donne une nouvelle occasion aux parlementaires ultramarins d'exprimer leur désir patriotique. Le député guadeloupéen Gratien Candace intervient à la Chambre des députés en janvier 1913 en ces termes :

Ne point appliquer aux colonies assimilées la loi sur le recrutement militaire, c'est non seulement priver la France d'un contingent supplémentaire dont elle a de plus en plus besoin, mais c'est encore aller à l'encontre des désirs, toujours vivement exprimés, par nos compatriotes nés et vivant dans nos possessions lointaines. Ceuxci veulent être soldats : ils considèrent comme un amoindrissement moral le fait de ne point être appelés sous les drapeaux et cela que par ailleurs, en Afrique 
occidentale, on pratique le recrutement forcé chez les populations noires non encore françaises au sens légal du $\operatorname{mot}^{10}$.

\section{aux colonies tous les textes relatifs à l'organisation militaire promulgués en France} depuis 1905.

\section{La mobilisation des soldats guadeloupéens}

Les premiers conscrits guadeloupéens, ceux de la classe 1912 nés en 1892, partent les 18 octobre (fig. 2) et 3 novembre 1913. Ces jeunes hommes sont conscients que leur mobilisation revêt une importance historique pour la Guadeloupe dans son rapport avec la métropole et ils témoignent leur attachement aux valeurs du schœlcherisme en offrant au musée Schœlcher ${ }^{11}$ à l'occasion d'une cérémonie donnée pour leur départ, une plaque en zinc peinte (fig. 3) qui porte cette inscription solennelle : «À Victor Schœlcher / Les $1^{\text {ers }}$ conscrits guadeloupéens / 2 novembre 1913 / offert par la Mutualité ouvrière ».

Figure 2

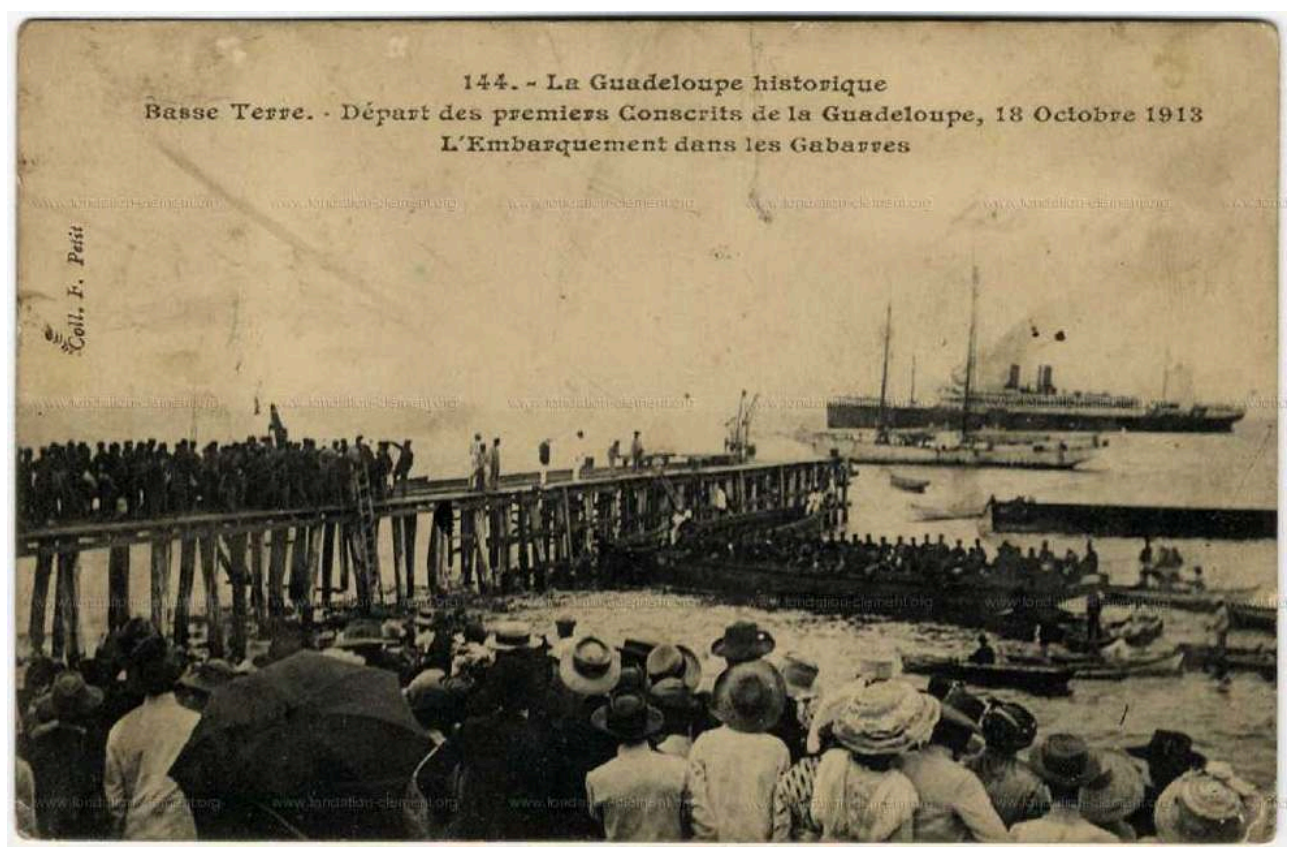

La Guadeloupe historique. Basse-Terre. Départ des premiers conscrits de la Guadeloupe le 18 octobre 1973. L'embarquement dans les gabarres. Carte postale, collection Loïs Hayot, fondation Clément, $n^{\circ}$ C014/06/087.

(c) Fondation Clément. 


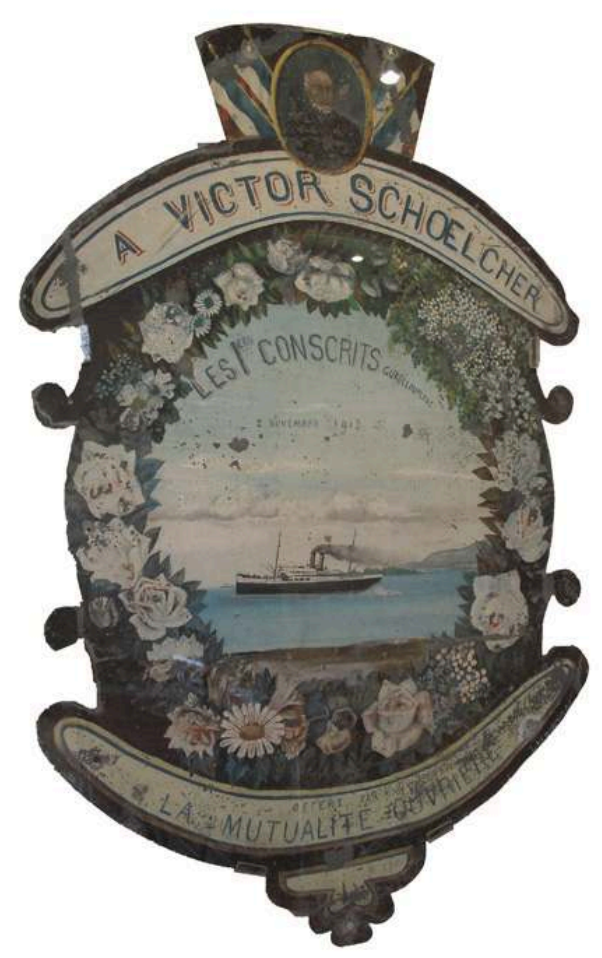

Plaque en zinc peinte, 1913. Hauteur : 0,80 m. Musée Schœlcher, Pointe-à-Pitre.

(c) Conseil général de la Guadeloupe.

par premiers conscrits sont d'abord dirigés vers la Martinique avant d'être transportés fusil, galvanisés par les fêtes aux élans patriotiques données en leur honneur, assurés de l'importance de leur mission et du soutien sans faille de l'arrière.

La voie à suivre est montrée par d'anciens combattants de la guerre de 1870, anciens engagés volontaires portant costumes militaires et médailles, venus raconter aux partants leur expérience du feu et leurs faits d'armes glorieux. Celui qui sera le héros guadeloupéen de la Première Guerre mondiale et le premier Noir de Guadeloupe à avoir fait Polytechnique, le capitaine de vaisseau Camille Mortenol (1859-1930), livre ses conseils dans une brochure intitulée Conseils aux conscrits créoles. Malgré cela, ces jeunes qui pour la plupart quittent pour la première fois leur pays et leurs familles éprouvent de grandes difficultés d'adaptation. Pour ceux qui ne parlent que le créole, la première barrière est linguistique. Bien que le conseil de révision ait soigneusement sélectionné les hommes en bonne santé, le changement de régime alimentaire contribue à affaiblir leurs défenses immunitaires dans le contexte du casernement. En outre, leur arrivée au mois de novembre n'est pas de nature à faciliter leur acclimatation. L'hiver 1913-1914 est particulièrement froid et de nombreux conscrits sont victimes de maladies respiratoires, dont ils succombent parfois, avant même la déclaration de la guerre. Certains journaux s'en émeuvent, d'autres y trouvent une occasion de moquerie, doutent de leur valeur militaire et de l'« intérêt » pour la nation d'avoir consenti un tel effort financier afin de satisfaire aux désirs patriotiques des anciennes colonies. Ainsi, Le Petit Marseillais écrit : "Ils ont des qualités sans doute. Ce sont peut-être de bons ouvriers, d'excellents travailleurs, mais ce ne sont pas des soldats $^{12} »$. Les 
parlementaires antillais qui ont si vivement soutenu l'engagement des jeunes créoles sont blessés par ces affirmations et choqués par le nombre de décès.

Face à cette hécatombe, le ministère de la Guerre décide d'organiser le rapatriement des réformés en état de voyager, qui subissent une mise en quarantaine à leur arrivée sur le sol natal ${ }^{13}$, tandis que le reste du contingent est dirigé vers la Tunisie et l'Algérie.

Si certains au sein de l'état-major s'interrogent encore sur l'opportunité de la mobilisation des soldats créoles, la question est rapidement balayée par la déclaration de guerre le 4 août 1914 et, dès le début de l'année 1915, il faut compenser les pertes énormes de l'armée française par l'arrivée de nouvelles recrues. Les mairies sont chargées d'organiser le recensement de tous les citoyens mobilisables ayant entre 18 et 45 ans et le conseil de révision est de moins en moins regardant sur les aptitudes physiques des mobilisés. Conscrits guadeloupéens, hommes des troupes coloniales en résidence à la Guadeloupe, engagés d'avant-guerre et nouveaux engagés alimentent ainsi le contingent créole ${ }^{14}$. Les soldats antillais sont acheminés vers le sud de la France pour être affectés essentiellement dans des régiments d'infanterie coloniale basés à Lyon, Toulon, Marseille, Perpignan et Bordeaux. Il est prévu qu'ils soient envoyés pour un tiers sur les fronts du nord-est de la France et pour les deux tiers sur le front d'Orient, particulièrement dans les Dardanelles. Beaucoup font partie des poilus d'Orient des $3^{\mathrm{e}}$ et $4^{\mathrm{e}}$ zouaves. De nombreux Guadeloupéens du $2^{\mathrm{e}}$ régiment de marche d'Afrique périssent dans les Dardanelles en avril-mai 1915, et sur la plage de Gallipoli, où la dysenterie et la jaunisse font autant de morts que les combats, véritable tombeau de l'armée d'Afrique.

\section{Le soutien de l'arrière}

Malgré l'éloignement géographique des zones de front et pendant toute la durée de la guerre, l'opinion publique guadeloupéenne soutient avec ardeur les enfants du pays et exprime sa reconnaissance envers leur sacrifice, dans un contexte où la censure qui s'applique à la presse empêche tout article démobilisateur. En outre, la situation économique de l'île profite de l'augmentation des contingentements de rhum agricole grâce aux commandes passées par l'armée pour « soutenir » les soldats.

Des manifestations populaires accompagnent les départs et sont encouragées par les autorités locales. Le Nouvelliste du 24 octobre 1913 rapporte la parole du gouverneur de la Guadeloupe qui invite « la population à célébrer cet événement mémorable qui, en conformité avec l'œuvre législative de Victor Schœlcher, vient affirmer l'égalité de nos citoyens guadeloupéens devant les devoirs et les droits de la loi militaire comme devant ceux des lois civiles de la République. » Il recommande aux «mandataires élus du pays, députés, conseillers généraux, maires [...] de s'y associer unanimement ».

De son côté, le sénateur guadeloupéen Henry Bérenger se préoccupe de fournir une assistance aux jeunes soldats éloignés de leurs familles et charge le Comité de l'Amérique française et des anciennes colonies installé à Paris, dont il est le président, de leur apporter un soutien moral et matériel. Les Guadeloupéens participent aux souscriptions, en particulier celle de l'emprunt de la Défense nationale, pour venir en aide aux « $\mathrm{POM} »$, les poilus d'Outre-mer. 


\section{Les formes de la commémoration en Guadeloupe}

\section{durablement rompu par la perte de 1,4 millions d'hommes; elle compte 4,3 millions de} blessés, dont certains ne pourront plus jamais travailler, son économie est en panne, tous les secteurs, y compris l'agriculture, manquent de main d'œuvre. Très lourdement endettée, la France oublie l'effort de ses poilus d'outre-mer et songe à céder à ses créanciers américains la Guadeloupe et la Martinique. Même si cette idée est vite abandonnée - on imagine la colère des Antillais si un tel projet avait abouti - le changement statutaire des îles du Vent n'est plus à l'ordre du jour. Mais la nation meurtrie dans sa chair éprouve le besoin de se retrouver et de donner du sens au sacrifice de toute une génération. En ce qui concerne la Martinique et la Guadeloupe, le sentiment d'appartenance nationale trouve à s'exprimer et à se renforcer dans un symbole fort : l'adoption de deux villages de la Meuse sinistrés, Étain et Neuvilly. À ce titre, le monument aux morts de Neuvilly-en-Argonne (1926), élevé grâce aux souscriptions guadeloupéennes, constitue l'un des premiers cénotaphes de l'archipel. À l'occasion de son inauguration le 16 mai 1926, le président Poincaré prononce ces paroles solennelles : « La Guadeloupe ne sépare pas son sort du nôtre et elle estime avec raison qu'elle fait partie intégrante de la Patrie dont elle porte les couleurs ».

La décennie 1919-1929, durant laquelle plus de la moitié des monuments aux morts de Guadeloupe sont érigés, correspond, à l'instar de la métropole, à la période d'édification la plus intense. Il s'agit dans un premier temps de plaques commémoratives et de calvaires qui apparaissent dans les cimetières. Mais ce sont les monuments «fondateurs» de Pointe-à-Pitre et de Basse-Terre qui marquent réellement les débuts de la commémoration publique et officielle en Guadeloupe. Dans leur sillage, plusieurs communes se dotent de monuments plus importants, la plupart commandés en France métropolitaine sur catalogue. Un nouvel élan commémoratif est donné ensuite dans les années 1930, dans le contexte des reconstructions consécutives au cyclone dévastateur de 1928 et aux commémorations du Tricentenaire du rattachement des Antilles et de la Guyane à la France ${ }^{15}$, sur fond de crise sociale et économique. Les monuments édifiés après la Seconde Guerre mondiale n'ont pas été intégrés à cette étude, qui ne vise pas non plus l'exhaustivité.

\section{Les débuts de la commémoration}

\section{La loi Poincaré et son application en Guadeloupe}

La loi Poincaré du 25 octobre 1919 s'applique également à l'Algérie et aux colonies, en vertu de son article 7. En instituant la tenue des livres d'or sur lesquels sont inscrits les noms des morts pour la France, elle jette les bases de l'édification des monuments commémoratifs. La guerre de 1870 et le républicanisme patriotique de la $\mathrm{III}^{\mathrm{e}}$ République avaient déjà suscité l'apparition d'une importante statuaire publique - monuments aux morts de la guerre, monuments à la gloire de la République, bustes de Marianne ${ }^{16}$. Toutefois l'ampleur de ce mouvement n'a rien de comparable avec la frénésie commémorative qui touche la quasi-totalité des communes de France après 1918. Ces formes de la commémoration ne sont pourtant pas exigées, ni même mentionnées, par la loi Poincaré, et relèvent de la seule volonté des politiques publiques locales, des associations d'anciens combattants, et de la société civile. Ces initiatives sont 
cependant soutenues par l'article 5 qui prévoit que « Des subventions seront accordées par l'État aux communes, en proportion de l'effort et des sacrifices qu'elles feront en vue de glorifier les héros morts pour la patrie. La loi de finances ouvrant le crédit sur lequel les subventions seront imputées réglera les conditions de leur attribution ». Le montant de ces subventions d'État n'est fixé qu'en juillet 1920, selon une méthode de calcul fixée par un barème basé sur la proportion du nombre de morts dans la commune par rapport au recensement de 1911. Il pouvait se combiner avec un second barème tenant compte de la richesse par habitant de la commune.

Quoi qu'il en soit, cette dotation, dont on ignore en l'état actuel des connaissances si elle a pu bénéficier aux communes guadeloupéennes, demeure modeste et ne représente que $5 \%$ à $25 \%$ du coût du monument aux morts. Elle cesse d'ailleurs progressivement d'être versée dès 1925 , comme le soulignent à regret les associations d'anciens combattants.

\section{Le rôle des communes et du gouverneur}

En dépit des difficultés financières, de l'éloignement des zones des combats, du nombre moins important de victimes, la quasi-totalité des communes de Guadeloupe disposent d'un monument aux morts de la guerre, qu'il prenne la forme d'une simple plaque commémorative ou d'un monument historié.

Les mairies, qui déjà s'étaient vues chargées de l'organisation du recensement des conscrits, vont être au cœur du processus commémoratif. Peu portée par la ferveur populaire, la commémoration est le fait de la volonté des élus et s'inscrit dans la logique de la pensée assimilationniste ${ }^{17}$. La recherche de financements est une préoccupation constante pour les communes qui organisent des souscriptions publiques et votent des fonds spécifiques pour l'érection des monuments. Plusieurs notes de la préfecture de Guadeloupe témoignent des mêmes préoccupations. Le gouverneur joue en effet un rôle essentiel en Guadeloupe où il n'existe pas, comme en métropole, de commission départementale chargée de l'examen des projets de construction des monuments aux morts. Il exerce un contrôle direct sur ces dépenses exceptionnelles des communes et délivre les autorisations pour les lancements de souscriptions publiques ${ }^{18}$. Il intervient également dans la gestion des problèmes liés à la commande, tels que le respect des délais et le paiement ${ }^{19}$. Dans une circulaire de 1922, le gouverneur Robert exhorte ainsi les maires à organiser des événements afin de relancer les souscriptions, et à inscrire des participations à la construction de monuments au budget municipal. Or ces communes sont pauvres et souffrent d'un sous-équipement considérable, qui ne sera qu'en partie rattrapé à partir des années 1930. Ces difficultés de financement peuvent expliquer les délais parfois très longs que l'on observe entre la décision et la réalisation des monuments aux morts, comme aux Abymes, où dix ans s'écoulent entre l'annonce du projet et sa concrétisation.

\section{Le rôle de l'Église}

Avant même l'investissement des communes, les premières commémorations sont initiées par l'Église, avec la pose de plaques et l'édification de calvaires dans les cimetières paroissiaux. Le premier monument proprement dit est celui du Sacré-Cœur de l'évêché de Basse-Terre, inauguré le 27 juillet 1919 par l'évêque, monseigneur 
Genoud. Ce dernier souhaite intégrer à la construction de ce monument envisagé dès 1916 une dimension commémorative lui permettant d'associer la célébration de la foi chrétienne et celle de la Patrie. Trois hautes plaques de marbre gravées aux noms des soldats guadeloupéens morts pour la France présentés en colonnes, par commune et par ordre alphabétique, sont ainsi apposées sur la partie basse du mur de façade. À la même époque, une plaque de marbre plus conventionnelle est posée à l'église SaintPierre et Saint-Paul de Pointe-à-Pitre (disparue). Il apparaît cependant très vite que ces listes des noms des disparus sont incomplètes.

\section{Un exemple précoce : la tombe-calvaire de Saint-Louis de Marie-Galante}

Dans ces tous premiers moments de la commémoration en Guadeloupe, le monument aux morts du cimetière de Saint-Louis de Marie-Galante occupe une place singulière, à mi-chemin entre le public et le religieux. Outre sa grande précocité - il est inauguré le 19 octobre 1919, il est édifié à l'initiative d'un particulier, Joseph Brisacier. Enfin, il se distingue également par sa forme peu fréquente, la tombe-calvaire ${ }^{20}$.

Trois ans après cet exemple précoce, la commune de Gourbeyre inaugure le 11 novembre $1922^{21}$ un monument aux morts (disparu) en forme d'obélisque. Vendu sur catalogue, facile à mettre en œuvre, et pour tout dire économique, l'obélisque sur piédestal sans représentation figurative est le type de monument le plus répandu dans les petites communes de France. Cependant cette forme simple est peu significative en Guadeloupe où les communes privilégient rapidement les formes historiées. TroisRivières inaugure le $1^{\text {er }}$ février 1923 un obélisque agrémenté de figures de poilus (disparu), puis Saint-François le 27 janvier 1924 inaugure un intéressant groupe sculpté (fig. 4) inspiré du motif de la Pietà ${ }^{22}$. Mais la dynamique commémorative n'est véritablement lancée qu'après l'installation des monuments de Pointe-à-Pitre et de Basse-Terre, inaugurés en 1925 et 1926. 
Figure 4

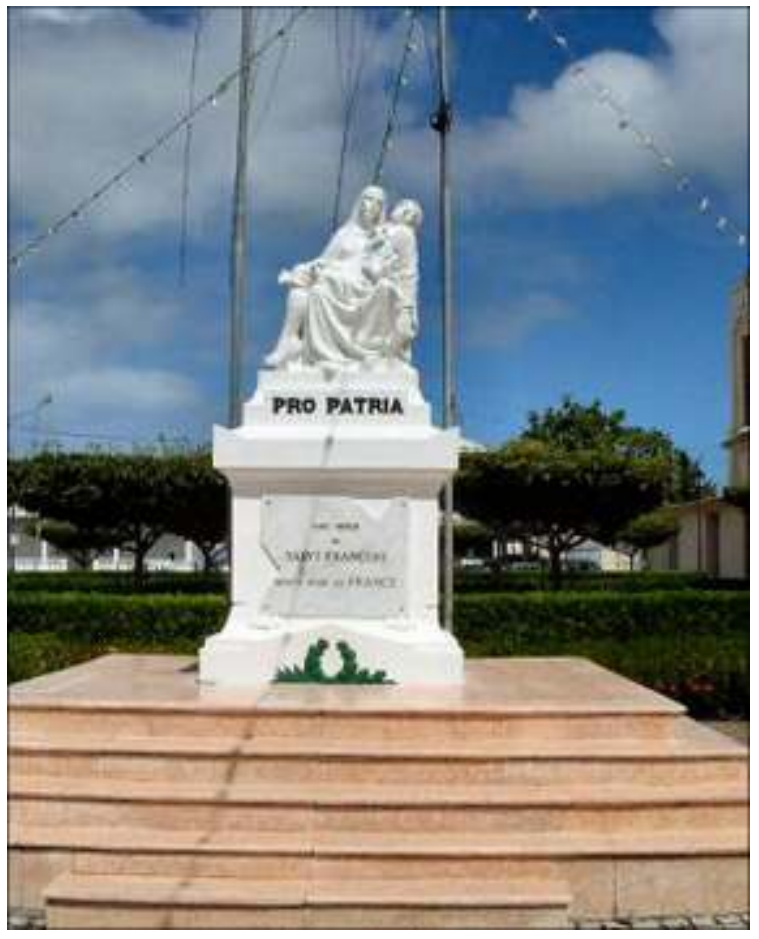

Saint-François, monument aux morts, 1924.

PHOT. BLAUDET, B., GENWEB. (c) B. BLAUDET.

31 De manière concomitante avec l'édification de ces deux monuments, la Guadeloupe témoigne de son appartenance à la Nation à travers un autre symbole fort, le financement par souscription du monument aux morts du village qu'elle parraine, Neuvilly-en-Argonne, dans la Meuse. À l'occasion de son inauguration le 16 mai 1926, le président Poincaré prononce ces paroles solennelles : «La Guadeloupe ne sépare pas son sort du nôtre et elle estime avec raison qu'elle fait partie intégrante de la Patrie dont elle porte les couleurs ».

\section{Les monuments fondateurs : monuments aux morts de la guerre de 14-18 de Pointe-à-Pitre et Basse-Terre, ou le Deuil et la Victoire}

Basse-Terre et Pointe-à-Pitre, en tant que chefs-lieux des deux arrondissements, ont vocation à représenter l'ensemble des Guadeloupéens touchés par la guerre. Le projet commémoratif y est donc plus ambitieux et est porté par le gouverneur Jocelyn Robert, qui préside le Comité pour le monument aux morts. Ce dernier adresse aux maires de Guadeloupe une lettre au sujet de la souscription publique qui doit permettre de financer ces deux monuments, dans laquelle il indique que les sommes collectées jusqu'alors sont importantes mais insuffisantes pour faire l'acquisition des œuvres retenues par le Comité, lequel a " porté son choix sur deux œuvres d'art qui certes, se distinguent moins par des proportions grandioses que par la pureté et la simplicité émouvante des lignes et par l'heureuse harmonie de l'ensemble, mais dont le coût dépasse sensiblement tout de même le montant des fonds recueillis jusqu'ici ${ }^{23}$. Au 
nom du Comité, le gouverneur sollicite donc un effort financier supplémentaire pour acquérir deux œuvres du sculpteur Hippolyte Galy.

Ces monuments de Basse-Terre et de Pointe-à-Pitre constituent les deux éléments fondateurs de la commémoration publique de la Grande guerre en Guadeloupe au début des années 1920. Ils sont sans doute aussi les deux monuments les plus coûteux édifiés dans la colonie et, s'ils ne constituent pas comme nous le verrons des œuvres tout à fait originales, ils sont dus à un sculpteur réputé en métropole. Hippolyte Galy (1847-1929) ${ }^{24}$ livre deux œuvres monumentales en conformité avec l'esthétique de son temps, qui mettent en scène des allégories féminines aux formes voluptueuses. Sur un mode expressif assez grandiloquent, elles illustrent chacune les deux thèmes privilégiés de la commémoration de la guerre : le deuil et la victoire.

\section{Le monument aux morts de Pointe-à-Pitre}

Le monument de la place de la Victoire à Pointe-à-Pitre (fig. 5) est inauguré en premier, le 11 novembre $1925^{25}$. Cette sculpture en marbre de Carrare, parfois appelée la Douloureuse de la Pointe-à-Pitre, est une allégorie de la Nation en deuil.

Figure 5

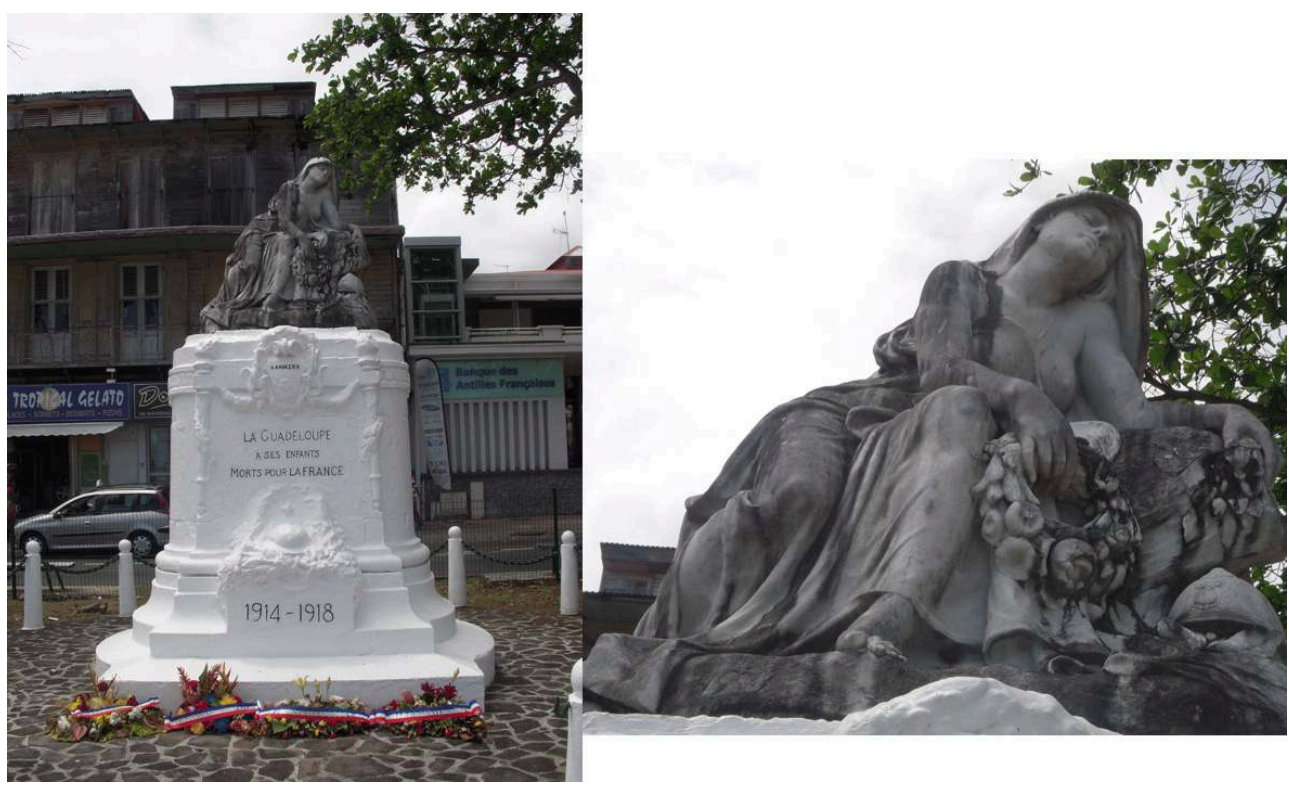

Hippolyte Galy : «La Douloureuse de la Pointe-à-Pitre », Monument aux morts, Place de la Victoire, Pointe-à-Pitre, 1925.

Phot. Dussauge, M., 2014. (c) M. Dussauge.

Une femme vêtue à l'antique est assise et tient une couronne de fleurs. La posture de son corps incliné par le poids du chagrin, l'expression de son visage, expriment l'affliction la plus profonde. L'absence du corps du martyr, seulement symbolisé par un casque de soldat posé à ses pieds, renforce le sentiment de perte. Le sujet de la Douloureuse illustre une tendance pacifiste de la commémoration. Trois ans avant Pointe-à-Pitre, Galy en livre un exemplaire à Montluçon (Allier), ville qui s'était distinguée avant guerre par l'importance de ses manifestations pacifistes. Le modèle en plâtre est présenté en 1921 à Paris au Salon de la société des artistes français ${ }^{26}$, et l'année suivante Galy expose sa version définitive en calcaire ${ }^{27}$. Il faut préciser ici que 
ce Salon, qui se tenait au Grand Palais, constitue alors l'épicentre de l'art officiel. Dès sa réouverture en 1919, il accorde une large place aux artistes démobilisés et entretient la mémoire des artistes morts pour la France. La section de sculpture des Artistes français y trouve une vitrine prestigieuse pour l'exposition d'une infinité de modèles de monuments commémoratifs : maquettes, modèles en plâtre ou prêts à être installés. Cette abondance, voulue par les organisateurs du Salon et souvent déplorée par les critiques, illustre aussi l'incroyable gisement économique que représente dans les années 1920 la commande de monuments aux morts. L'activité est telle qu'elle encourage des pratiques quasi industrielles et Hippolyte Galy lui-même n'hésite pas à réutiliser certaines de ces compositions avec de légères variantes lui permettant de les présenter comme des originaux. La figure de la Douloureuse de Pointe-à-Pitre constitue ainsi le motif principal du monument aux morts de Guingamp ${ }^{28}$. Galy, qui le conçoit en 1922, la même année que le groupe de Montluçon, modifie un peu la position de l'allégorie qui tient sa tête, et représente le soldat non pas seulement par son casque, mais par son visage de profil.

Dans ces productions parfois répétitives, le piédestal peut être utilisé comme un élément permettant de singulariser le monument. Sur celui de Pointe-à-Pitre, l'inscription «KARUKERA» sur un cartouche est particulièrement intéressante puisqu'elle fait référence au nom amérindien de l'̂̂le et nous replonge à ses origines.

\section{Le monument aux morts de Basse-Terre}

Le monument de Basse-Terre (fig. 6), du même artiste, est plus imposant par sa taille, plus spectaculaire. Il se situe sur un registre très différent, combatif, mettant en scène la Nation victorieuse. Les difficultés posées par son installation ${ }^{29}$ peuvent expliquer que son inauguration - le 15 juillet $1926^{30}$ - ait été postérieure à celle du monument de Pointe-à-Pitre, et surtout le décalage avec l'année 1924 gravée au dos du monument.

Figure 6
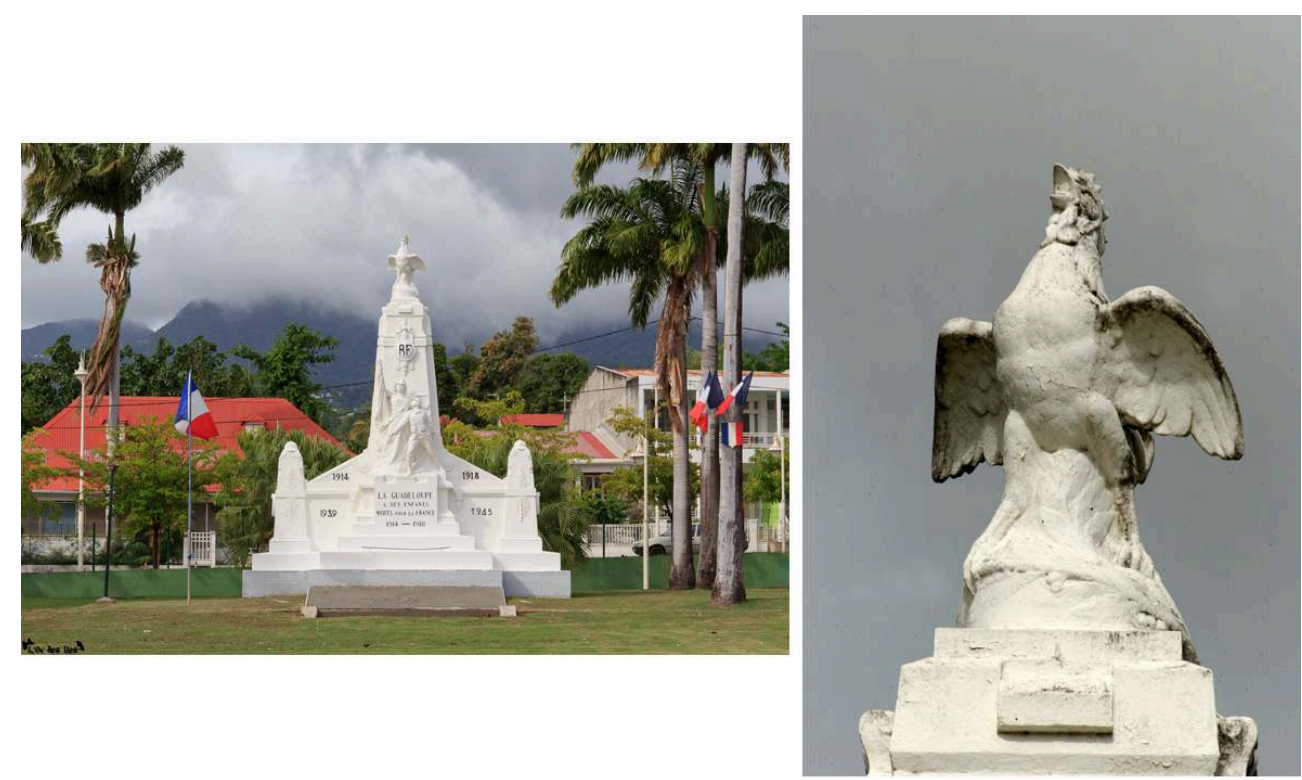

Hippolyte Galy, Monument aux morts de Basse-Terre, Champ d'Arbaud, 1926.

Phot. Peiré, J.-F., Inventaire général de Guadeloupe, 2002. ( I Inventaire général. 
Contrairement à Pointe-à-Pitre où le groupe sculpté semble en retrait, dans un angle de la place de la Victoire, il occupe ici une place centrale sur le Champ d'Arbaud. Ce vaste espace, proche de la plupart des bâtiments administratifs et créé vers 1780 , constituait un lieu de promenade sur lequel avaient lieu également des exercices et les parades militaires. L'allégorie de la Patrie, qui d'une main brandit un drapeau, affiche une expression triomphante. Elle passe un bras protecteur sur l'épaule d'un soldat qui offre sa poitrine au spectateur, en démonstration de son courage et de son sens du sacrifice. La composition pyramidale est dominée par un coq fièrement dressé sur ses ergots, juché au sommet d'un obélisque, symbole de la Nation victorieuse.

Ce coq gaulois conçu par Galy se retrouve au sommet d'un court obélisque également orné d'un buste de poilu en relief dans un médaillon, sur le monument aux morts de Vieux-Habitants (fig. 7) en 1930. Ce coq fait partie des œuvres d'Hippolyte Galy reproduites en série par les Marbreries générales Gourdon à Paris, qui les commercialisaient en les déclinant dans différents matériaux. Le monument aux morts de Bélesta dans l'Ariège en 1925 en est un exemple. Le coq de Galy figure également au catalogue des fonderies du Val d'Osne, sous le $\mathrm{n}^{\circ} 262^{31}$.

Figure 7

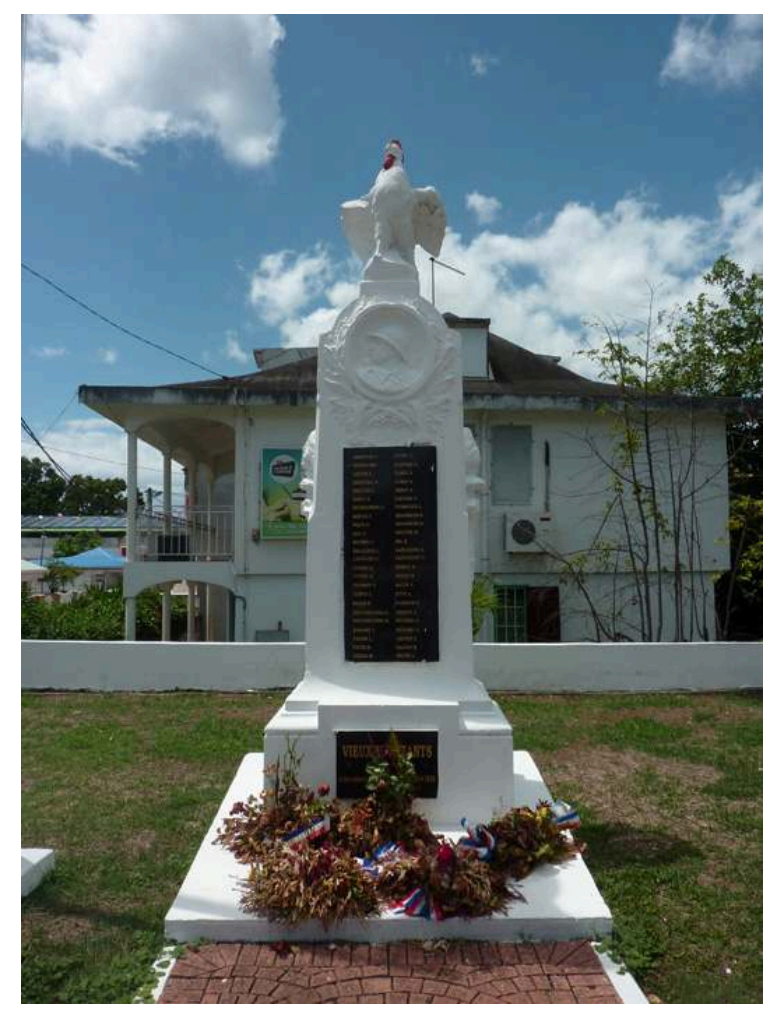

Vieux-Habitants, monument aux morts, 1930.

Phot. Dussauge, M., 2014. ㄷ M. Dussauge.

\section{Les Poilus de la période 1926-1930}

L'obélisque de Vieux-Habitants illustre une tendance observée sur les monuments aux morts édifiés en Guadeloupe au cours des années 1926-1932, celle du recours aux sculptures et ornements produits en série par des fonderies d'art et marbriers 
métropolitains. Commercialisés sur catalogues, combinés et déclinés dans différents matériaux et formats selon les moyens des commanditaires, certains modèles connaissent un tel succès qu'ils sont tirés à des centaines d'exemplaires ${ }^{32}$.

\section{Le Poilu mourant}

Les communes guadeloupéennes se tournent naturellement vers ce type de fournisseur. Ainsi, le monument aux morts de Petit-Bourg (fig. 8), inauguré le 15 août 1926 par le maire M. Larifla et le gouverneur M. Gerbinis ${ }^{33}$ s'orne ainsi d'un Poilu mourant défendant son drapeau, tirage en galvano-bronze (agglomérat zingué recouvert d'une pellicule de cuivre) produit par les Marbreries générales de Paris $^{34}$. Cette entreprise spécialisée répond aussi bien aux demandes des particuliers qu'à celles des collectivités; elle soustraite la fabrication des éléments en bronze ou en fonte, ainsi qu'une partie de la statuaire, qui peut-être réalisée en Italie et particulièrement à Carrare pour les réalisations en marbre.

Figure 8

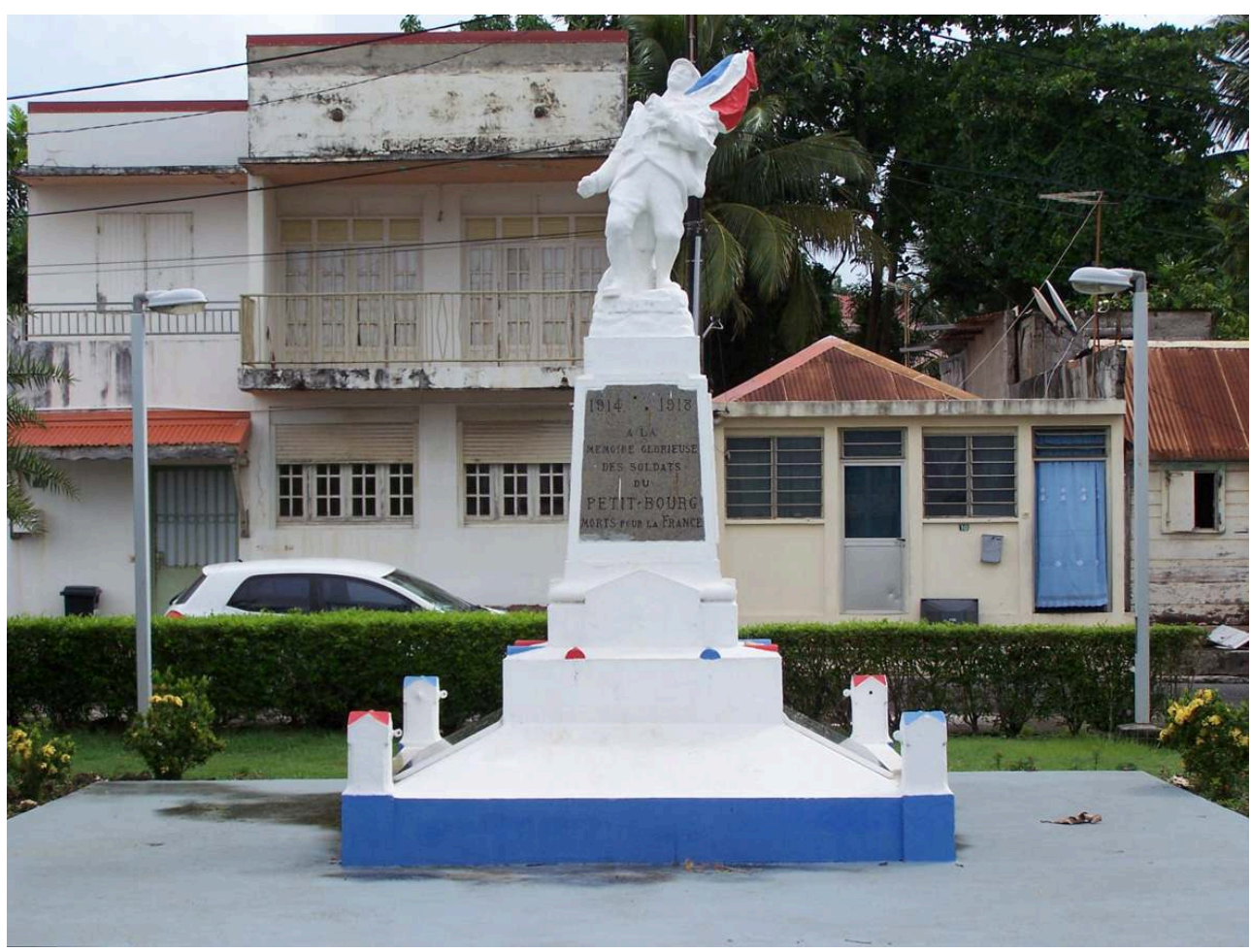

Petit-Bourg, monument aux morts, 1926

Phot. LPLT / Wikimédia commons, 2013. @ LPLT / Wikimédia commons.

Le modèle du Poilu mourant défendant son drapeau, décliné pour les Marbreries générales (fig. 9) en bronze, galvano-bronze, marbre et pierre reconstituée, est peut-être leur plus grand succès commercial. On le retrouve ainsi dans de nombreuses petites communes - plus de trente - de toutes les régions de France ${ }^{35}$. Dans les départements d'outre-mer, il orne le monument aux morts de Gros-Morne en Martinique. Il a également été commandé en 1923 par la commune de Saint-Joseph à La Réunion. La fortune de ce sujet tient peut-être au fait qu'il se situe à la frontière du réalisme et de 
l'idéalisation: il évoque directement la mort, tout en évitant de la représenter, et comme le résume Annette Becker, il est « le mourant toujours en vie » ${ }^{36}$.

Figure 9

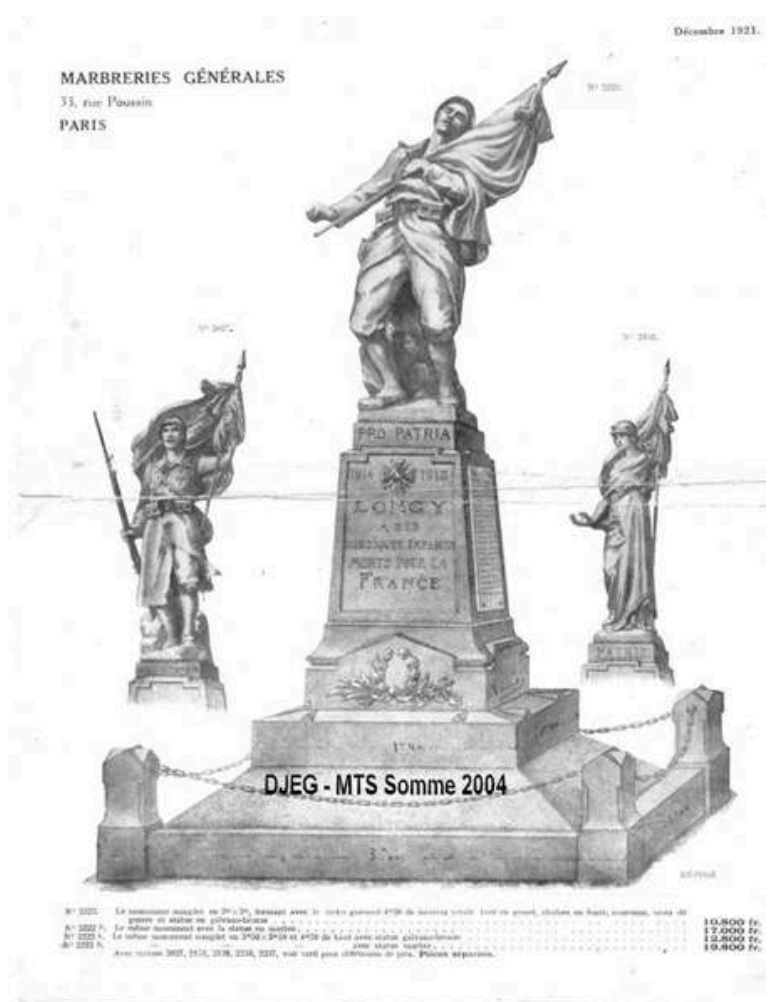

Modèle du Poilu mourant défendant son drapeau, des Marbreries générales.

Phot. Archives départementales de la Somme. (c) Archives départementales de la Somme.

Le Poilu mourant apparaît dans un autre monument aux morts de Guadeloupe, celui de Capesterre-Belle-Eau (fig. 10), inauguré le 23 janvier $1927^{37}$. Ce dernier combine sur un obélisque les deux thèmes majeurs de la commémoration évoqués plus haut, le deuil et la victoire. Au bord de la base de l'obélisque, symboliquement au bord du gouffre, se trouve le Poilu mourant, tandis qu'au sommet de l'édifice se dresse l'allégorie de la France - ou de la Victoire - tendant une couronne de lauriers au-dessus du soldat mortellement touché. Cette combinaison, qui résume l'antagonisme des émotions propres à la commémoration de la guerre, s'observe sur plusieurs monuments en métropole, comme à Cabourg (Calvados), Honnecourt-sur-Escaut (Nord), ou Arques (Pas-de-Calais). Sur ces monuments, qui proviennent également des Marbreries générales de Paris, la figure de la Victoire est sensiblement différente et se présente de profil $^{38}$. 
Figure 10

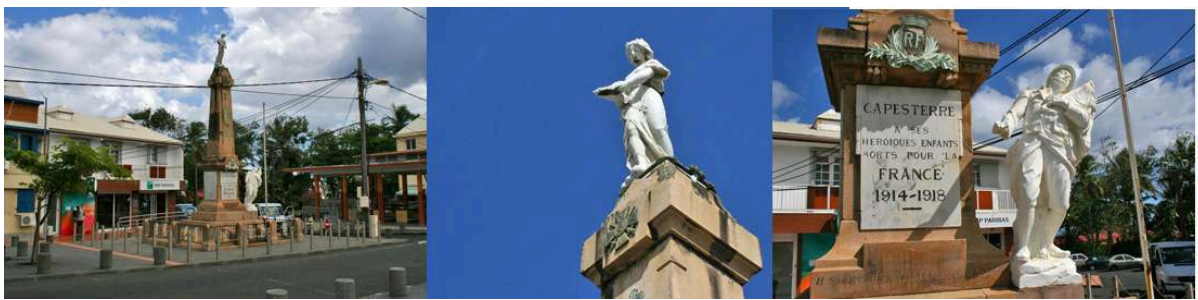

Capesterre-Belle-Eau, monument aux morts, 1927. Ensemble et détails.

Phot. Delassasseigne, Hervé. (c) Cheminbleu.com.

En revanche, les monuments de Walincourt-Selvigny (Nord), Villeréal (Lot-et-Garonne) (fig. 11) et Cuinchy (Pas-de-Calais), inaugurés en 1923 et 1924, présentent exactement la même Victoire que celle de Capesterre mais avec des ailes. Le dessin de l'obélisque est rigoureusement identique à Villeréal, Walincourt-Selvigny et Capesterre, ce qui laisse supposer que le monument de Capesterre a été en totalité commandé aux Marbreries générales de Paris.

Figure 11

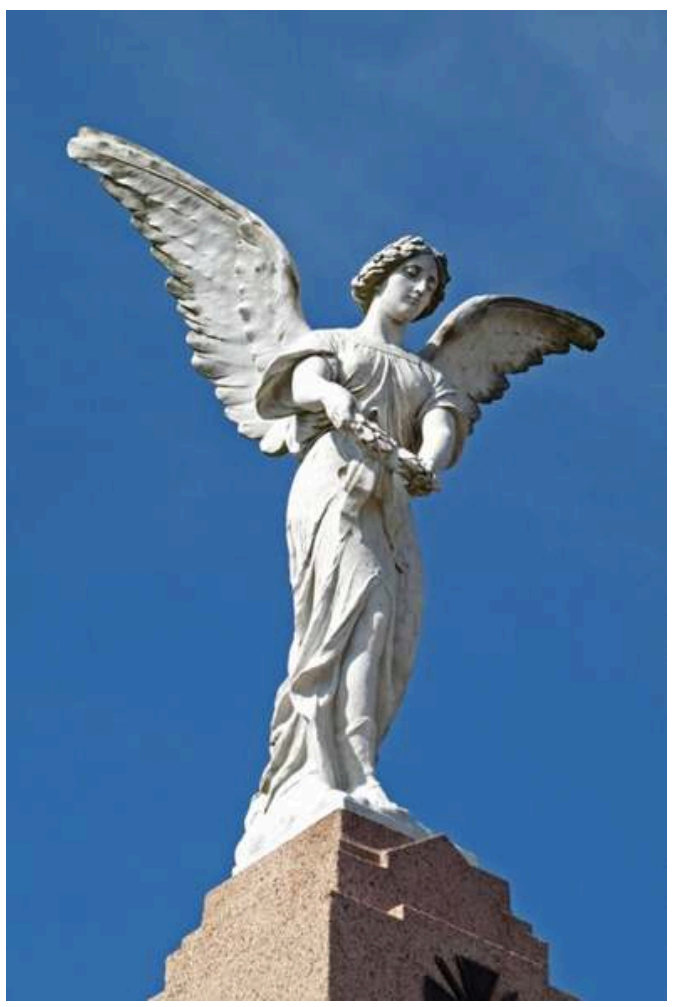

Villeréal (Lot-et-Garonne), monument aux morts, 1923. Détail.

Phot. Choubard, Alain, 2009. (c) Alain Choubard.

Les divers éléments décoratifs qui ornent le fût de l'obélisque sont encore des standards des catalogues des fonderies d'art. Palmes, croix de guerre et autres attributs sont déclinés dans différentes tailles, comme l'illustre le catalogue du Val d'Osne avec sa Croix de guerre $\mathrm{n}^{\circ} 305$. 
Une autre typologie de l'allégorie de la Victoire est illustrée par le monument aux morts de Goyave (fig. 12), la France remettant une couronne de lauriers, autre modèle du catalogue des Marbreries générales ( $n^{\circ} 2151$ ) produit dans les années 1920 et présent dans de nombreuses communes, comme à Thézac (Lot-et-Garonne), ainsi qu'en Martinique au Lamentin, et avec quelques variantes, au François.

Figure 12

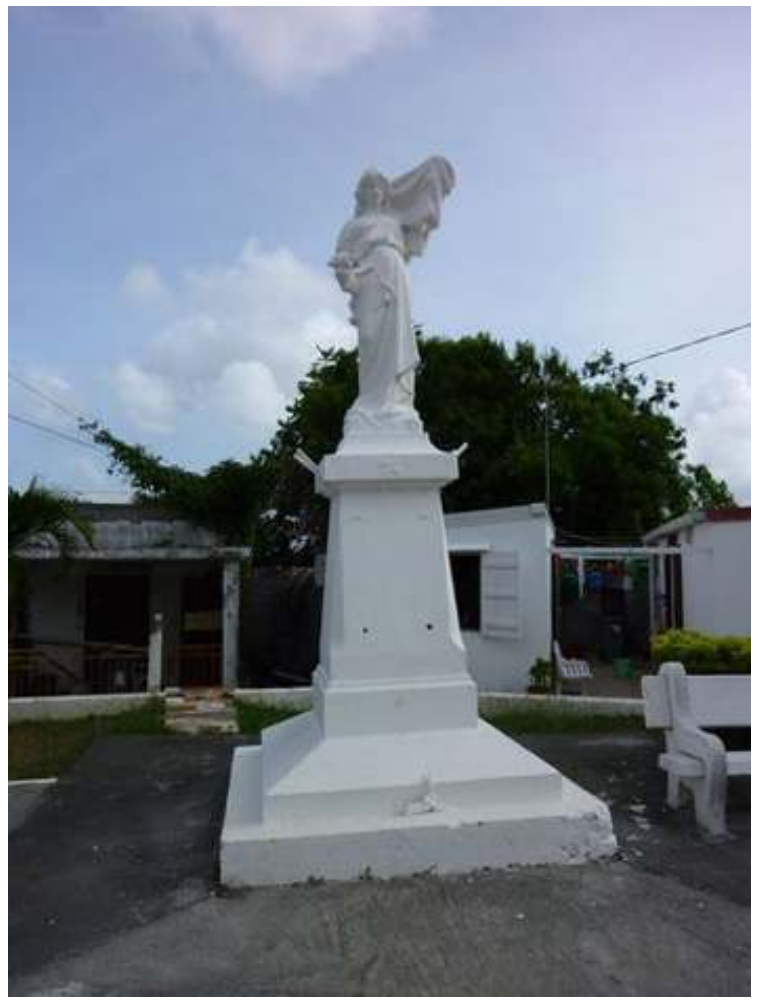

Goyave, monument aux morts.

Phot. Hamont, Laurence, 2012. (c) Laurence Hamont.

\section{Les monuments des années 1930 : I'influence de l'œuvre d'Ali Tur}

Le motif du Poilu mourant est, on l'a dit, privilégié par de nombreuses communes métropolitaines et choisi plusieurs fois en Guadeloupe dans les années 1920. Dans les années 1930, il disparaît au profit de la représentation du soldat-sentinelle, qui privilégie le thème de la vigilance et de la protection. C'est le cas du monument aux morts de Pointe-Noire (fig. 13), inauguré le 7 décembre 1930 ${ }^{39}$. Le modèle choisi est un autre grand succès des Marbreries générales, un soldat au repos tenant d'une main son fusil, de l'autre le drapeau ${ }^{40}$, présent dans une centaine de communes métropolitaines. Il est parfois décliné en marbre de Carrare, comme à Curciat-Dongalon (Ain). Celui de Pointe-Noire, en pierre reconstituée, a été recouvert d'une peinture polychrome, selon une pratique courante en Guadeloupe, mais demeure un soldat blanc. 
Figure 13

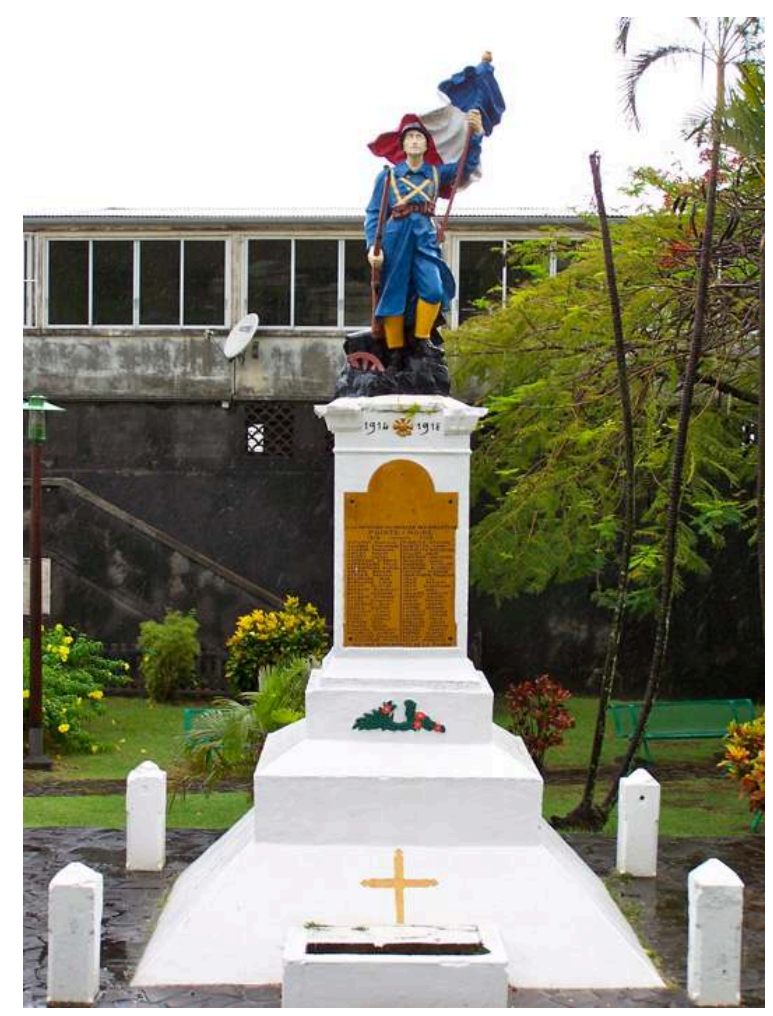

Pointe-Noire, monument aux morts, 1930.

Phot. LPLT / Wikimédia commons. C LPLT / Wikimédia commons.

Au milieu des années 1930 apparaît également une nouvelle génération de monuments aux morts, qui ne sont plus des répliques fabriquées en série mais des créations originales, très inspirées par l'esthétique Art déco. Leur émergence est favorisée par les reconstructions consécutives au cyclone de 1928 et soutenue par les célébrations du tricentenaire de la colonisation. Ces circonstances ont en effet permis l'attribution à la colonie de moyens supplémentaires dont certains centres urbains ont pleinement profité. Dans ce contexte, Ali Tur, architecte du ministère des Colonies appelé en 1929 par le gouverneur Tellier, va largement contribuer à l'instauration d'un nouveau style architectural, qualifié de moderniste. Engagé contractuellement pour une durée de quatre ans à la reconstruction des édifices gouvernementaux, il travaille également directement pour les communes de l'archipel. Ses bâtiments, en totale rupture avec l'architecture traditionnelle guadeloupéenne, répondent à un cahier des charges contraint : la solidité face aux risques cycloniques et sismiques, le confort thermique, la rapidité d'exécution et l'économie de moyens. Pour atteindre ces objectifs, Ali Tur met en œuvre les techniques les plus modernes et privilégie l'utilisation du béton armé.

Le travail accompli est colossal puisqu'on estime à 120 les réalisations d'Ali Tur et de son agence dans la période 1929-1937 : édifices gouvernementaux, mairies, palais de justice, tribunaux, perceptions, gendarmeries, bureaux de poste, maisons mortuaires, dispensaires, hôpitaux, écoles, marchés, presbytères, églises, logements, jusqu'au monument aux morts... Autant d'édifices qui par leur style et leur qualité architecturale contribuent, jusqu'à maintenant et de manière déterminante, à l'identité urbaine des communes de l'archipel. 


\section{Le monument aux morts du Lamentin}

50 Le centre-bourg du Lamentin, le seul qu'il ait entièrement reconstruit, constitue la meilleure illustration des conceptions architecturales d'Ali Tur. Le monument aux morts (fig. 14) est la pièce maîtresse de cet ensemble urbain protégé depuis 2009 au titre des monuments historiques. Tous les bâtiments - mairie, presbytère, groupe scolaire, église, justice de paix - s'articulent autour de ce symbole commémoratif édifié au centre d'une place aménagée en square (fig. 15).

\section{Figure 14}

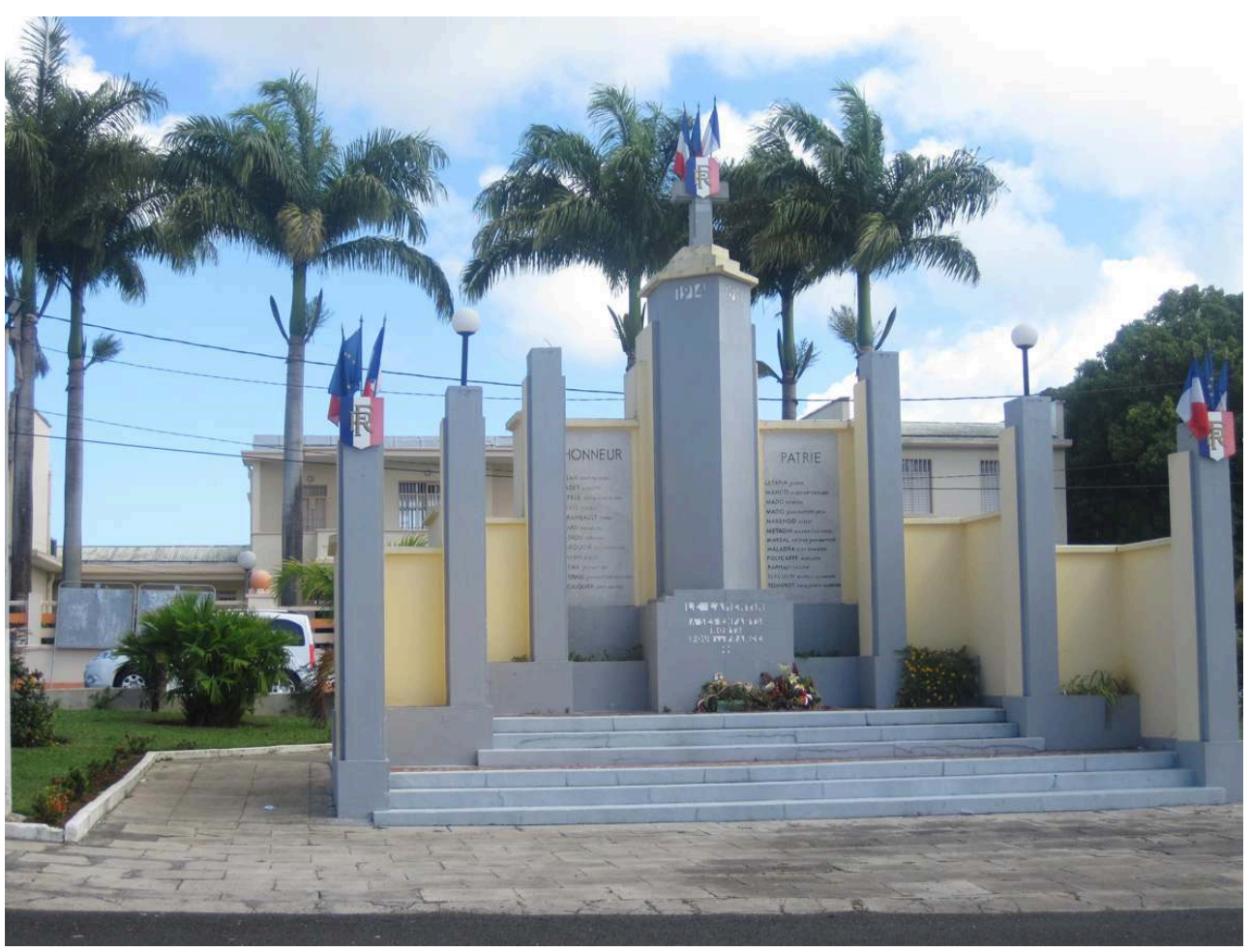

LAMENTIN, MONUMENT AUX MORTS, 1932.

Phot. DAC Guadeloupe. (c) DAC Guadeloupe. 
Figure 15

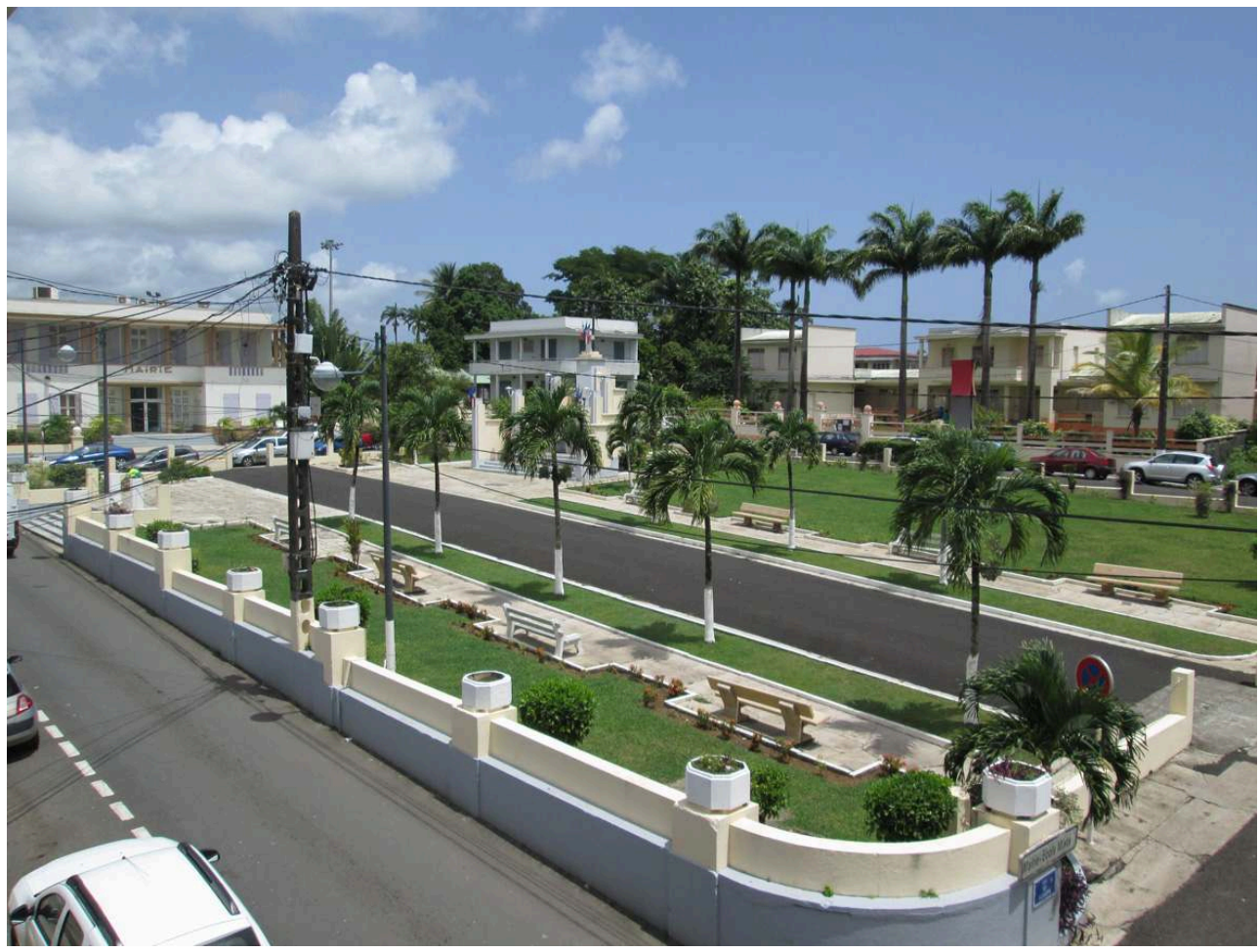

LAMENTIN, CENTRE BOURg.

Phot. Peiré, J.F., Inventaire général de Guadeloupe, 2002. (c) Inventaire général.

51 Le monument a été inauguré au cours de l'année 1933. Il combine deux types d'ouvrages commémoratifs : la stèle et le fût de l'obélisque. Occupant une emprise au sol importante, $10 \mathrm{~m}$ de large sur $6 \mathrm{~m}$ de profondeur, il est constitué d'un emmarchement central, de six poteaux de section carrée travaillés aux angles, distribués de part et d'autre d'un poteau central, dans une disposition qui évoque celle de deux bras qui s'ouvrent. Un muret plein en béton relie les poteaux les uns aux autres. Le poteau central, polygonal, présente une section plus large et est surmonté d'une croix, symbole religieux auquel fait écho l'église toute proche. Comme dans tout monument non figuratif, et d'une manière générale dans les constructions d'Ali Tur, les inscriptions formées par des lettres capitales en béton moulées jouent un rôle ornemental important.

52 Marqué par l'esthétique Art déco, Ali Tur livre au Lamentin un monument sobre, au caractère élancé et rythmé, bien éloigné du style du monument qu'il a conçu dans ses jeunes années pour la commune de Villers-Farlay (Jura) en 1921 (fig. 16). Le monument aux morts du Lamentin marque ainsi un tournant dans l'esthétique des édifices commémoratifs guadeloupéens. Ses lignes rigoureuses et efficaces inspirent encore quinze ans plus tard le monument aux morts du Gosier. Ali Tur pourrait également avoir dessiné le monument de Petit-Canal, qui décline sur un mode figuratif le style Art déco et influence fortement les monuments de Baie-Mahault, Port-Louis et d'AnseBertrand. 
Figure 16

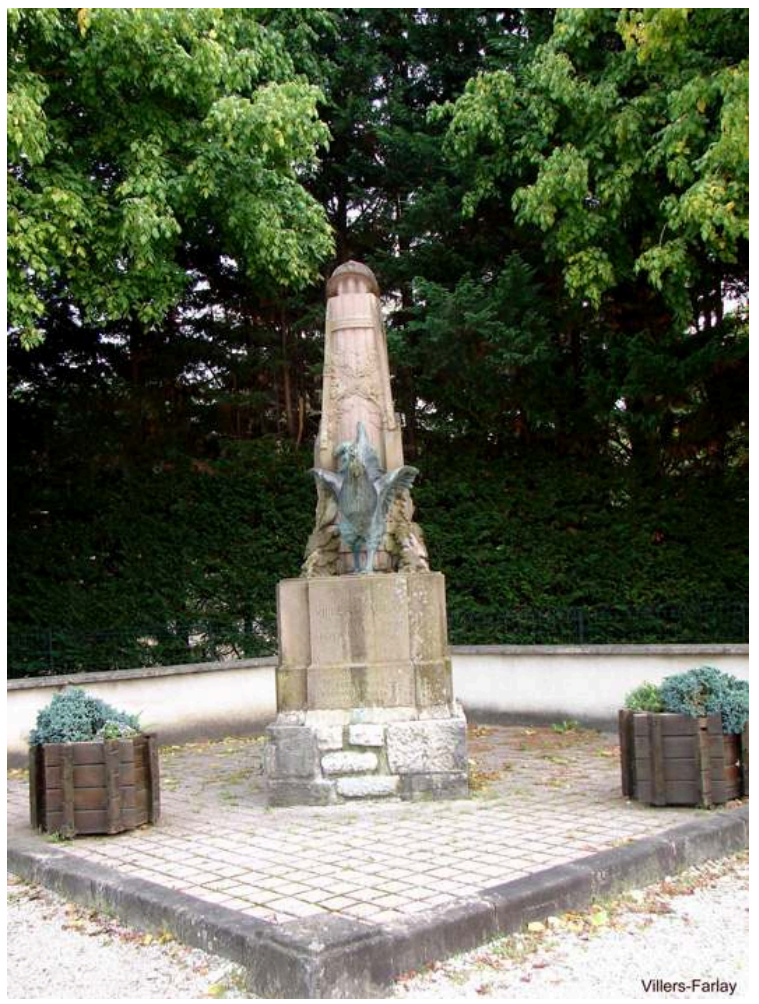

VILLERS-FARLAY (JURA), MONUMENT AUX MORTS, 1921.

PHOT. GIRARD, BERNARD, 2009. (C) BERNARD GIRARD.

\section{Les monuments figuratifs}

53 À Port-Louis (fig. 17), le monument inauguré le 11 novembre 1932 est érigé dos à la mer, dans l'axe de la rue de la mairie. Placé au centre d'un carré ceint par un muret bas, il se présente comme une grande stèle gardée par un poilu au repos, dressée sur une plate-forme à laquelle on accède par un emmarchement. Le contraste entre la vue magnifique sur la mer et les reliefs de la Basse-Terre, et la solennité du soldat, gardien de la mémoire des vingt enfants du pays dont les noms sont gravés dans le marbre, est saisissant. Enveloppé dans son manteau, ce dernier appartient bien aux troupes de l'infanterie coloniale, comme le désigne l'ancre de marine dessinée sur son casque. 
Figure 17

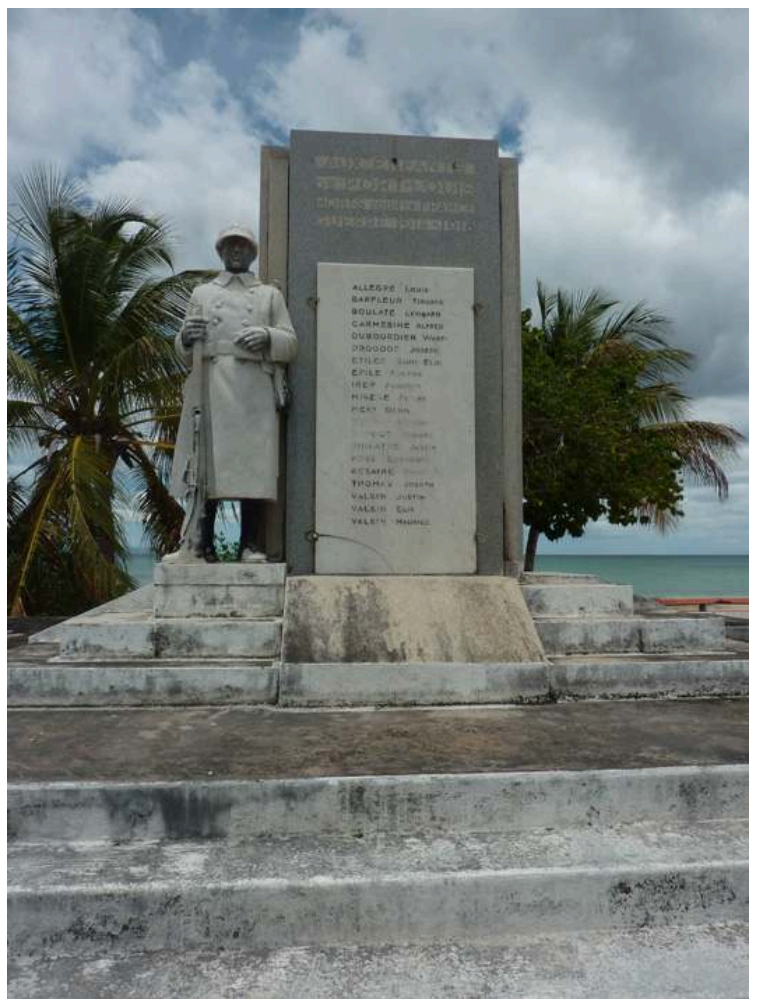

PORT-LOUIS, MONUMENT AUX MORTS, 1932.

Phot. Laborie, S., 2014. @ S. Laborie.

54 Si la stèle en granit n'est pas caractéristique du style d'Ali Tur, le monument pourrait cependant avoir été dessiné par lui. En effet, l'architecte avait été chargé d'agrandir l'église toute proche et avait construit le bâtiment de la Justice de paix qui jouxte le monument aux morts en 1930. La sculpture, ni signée ni documentée, est d'une grande qualité en dépit d'un encrassement préjudiciable ${ }^{41}$. Finement taillée dans un bloc de marbre blanc, elle présente des formes simples et un modelé délicat qui n'est pas sans évoquer le Poilu réalisé par Émile André Leroy à Petit-Canal.

Le monument de Petit-Canal (fig. 18) a été inauguré en 1936. Les auteurs connus de ce monument, l'entreprise de travaux publics Diligenti et le sculpteur Émile André Leroy, sont proches d'Ali Tur avec lequel ils collaborent à de nombreuses reprises. Ali Tur dessine également les plans de la mairie de Petit-Canal, édifiée en 1931 et qui jouxte le monument. On retrouve sur le monument aux morts le rythme ternaire qui lui est cher, les inscriptions en béton moulées, l'animation subtile des surfaces. Au-dessus des lettres «Souvenez-vous » inscrites sur une portion de cercle, la croix à degrés pourrait apparaître comme une signature de l'architecte, qui a placé des croix sur chacun de ses monuments aux morts. 
Figure 18

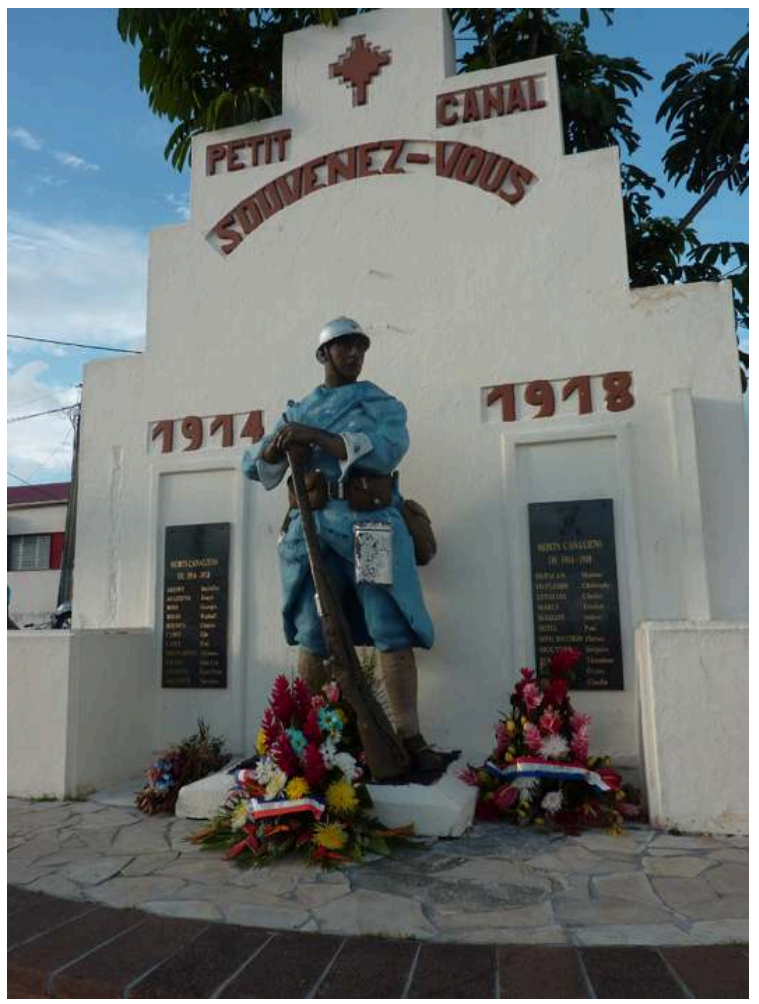

PETIT-CANAL, MONUMENT AUX MORTS, 1936.

Phot. Laborie, S., 2014. @ S. Laborie.

56 La statue en bronze - livrée avec retard par le sculpteur - n'était probablement pas peinte à l'origine. Le premier projet, connu par un dessin conservé aux archives départementales, montre le soldat au repos, regardant droit devant lui, tenant son fusil Lebel debout par le canon, posé au sol sur la crosse. Émile André Leroy adopte finalement une attitude plus libre, plus humaine, qui tranche avec les représentations solennelles du poilu au repos ou du poilu-sentinelle. Le soldat, la tête et le regard tourné vers le côté, les manches retroussées sur ses bras, les mains croisées sur le canon du fusil et les pieds solidement campés dans le sol, semble saisi sur le vif, vivant et proche de nous.

57 Le monument aux morts de Baie-Mahault (fig. 19) entretient une grande proximité stylistique avec celui de Petit-Canal. Inauguré le 12 janvier 1936, il a été dessiné par un disciple d'Ali Tur, l'architecte Edmond Mercier ${ }^{42}$. Il occupe un côté de la vaste place de la mairie et s'harmonisait avec le centre urbain reconstruit par Ali Tur en 1931 (mairie - aujourd'hui détruite, presbytère et église). Tournant encore une fois le dos à la mer, le monument est placé au fond d'un jardinet protégé par une clôture. Il se présente comme une haute stèle précédée d'un emmarchement et encadrée par deux murs bas. La stèle est ornée dans la partie supérieure d'une croix pattée et de l'inscription « À nos morts 1914-1918 ». Au centre du monument se dresse une statue représentant un soldat au garde-à-vous. 


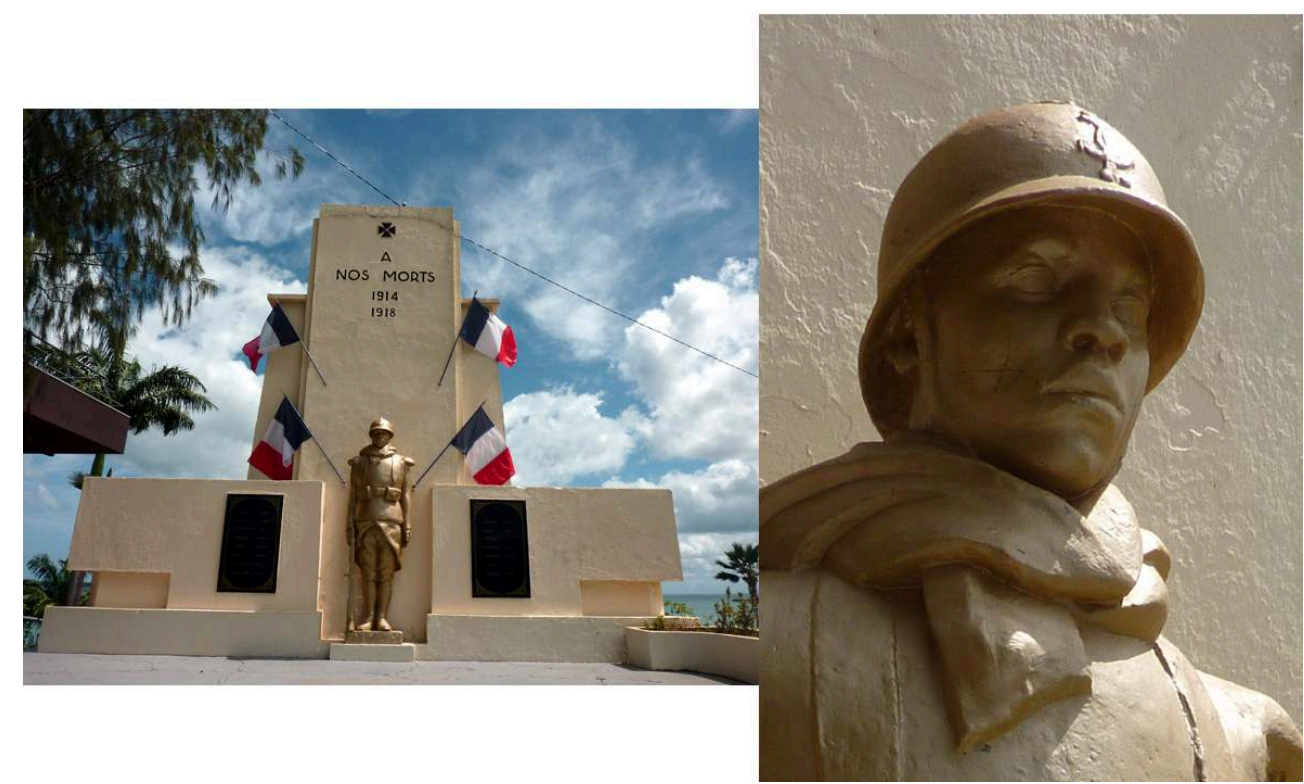

BAIE-MAHAULT, MONUMENT AUX MORTS, 1936.

Phot. Laborie, S., 2014. @ S. Laborie.

Ce monument réunit la qualité architecturale et l'intérêt iconographique. La sculpture en galvano-bronze est, comme à Petit-Canal, l'œuvre d'Émile André Leroy. En dépit de l'épaisse couche de peinture dorée qui la recouvre, sa qualité est incontestable. Ses formes simples, son économie de moyens, ne se font pas au renoncement de la précision iconographique. Ce soldat noir - un exemple très rare dans le corpus des monuments aux morts ultra-marins - appartient aux troupes coloniales des Poilus d'outre-mer, les POM, comme l'atteste l'ancre de marine qui orne son casque. Le détail de l'écharpe rappelle la difficulté de ces hommes des climats chauds à s'accoutumer au climat tempéré.

\section{Le monument aux morts d'Anse-Bertrand}

Rattaché à cette série de monuments figuratifs des années 1930, le monument aux morts d'Anse-Bertrand (fig. 20) présente une combinaison intéressante en associant une œuvre produite en série et un bas-relief original. Le Poilu au repos qui domine la composition est une sculpture produite en série par la Société anonyme des établissements métallurgiques Durenne d'après une œuvre de Léon Leyritz (1888-1976) réalisée en 1932. Ce modèle est également celui du monument aux morts de Saint-Louis de Marie-Galante. On le retrouve en Martinique à Morne-Rouge, et dans plusieurs communes hexagonales. Le bas-relief qui orne le soubassement du monument représente une victoire ailée, surplombant le corps d'un soldat mort auquel elle tend les palmes de la victoire, comme une promesse de vie éternelle. Le gisant repose sur un lit de feuilles, symbole de la régénération de la terre de France par le sacrifice des combattants. Cette œuvre de Louis Robert Bate (1898-1948) démontre par sa manière d'occuper l'espace autour d'une composition très serrée, son style graphique et son symbolisme, l'originalité de la démarche de ce sculpteur et ses qualités artistiques. Passé par l'atelier de Paul Landowsky (1875-1961), lequel a réalisé après guerre de nombreux monuments aux morts, Bate est également un grand dessinateur. Il se 
présente à des concours et obtient des bourses qui lui permettent de voyager en Espagne et en Afrique équatoriale. La Société coloniale des artistes français lui décerne en 1935 le prix de Guadeloupe, puis en 1938 le prix de l'Indochine ${ }^{43}$. Son passage en Guadeloupe lui a inspiré quelques aquarelles et statuettes, aujourd'hui conservées au musée du quai Branly à Paris.

Figure 20

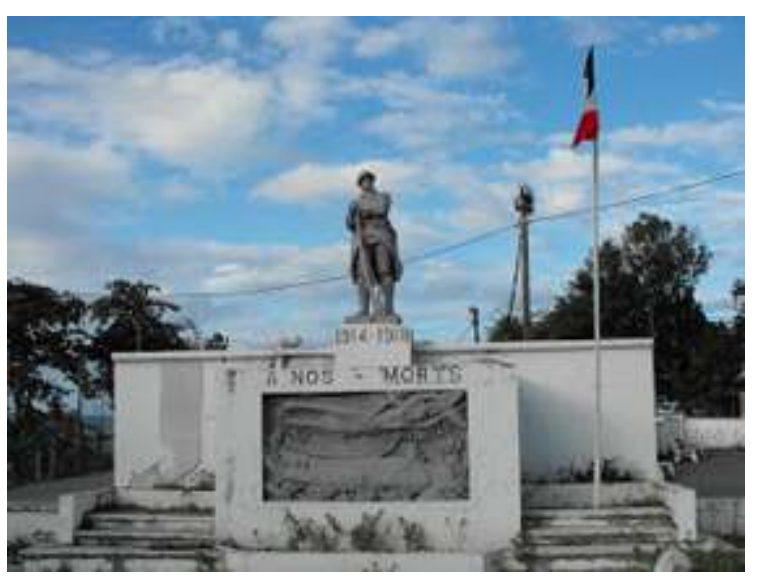

ANSE-BERTRAND, MONUMENT AUX MORTS, 1935 ?

Phot. DAC Guadeloupe. (C) DAC Guadeloupe.

\section{Le monument aux morts des Abymes}

Dans cet ensemble homogène de monuments datant du milieu des années 1930, le monument aux morts des Abymes (fig. 21), réalisé en 1937, occupe une place tout à fait singulière qui a justifié en 2013 une inscription au titre des monuments historiques, portant à deux le nombre de monuments aux morts protégés en Guadeloupe. 
Figure 21

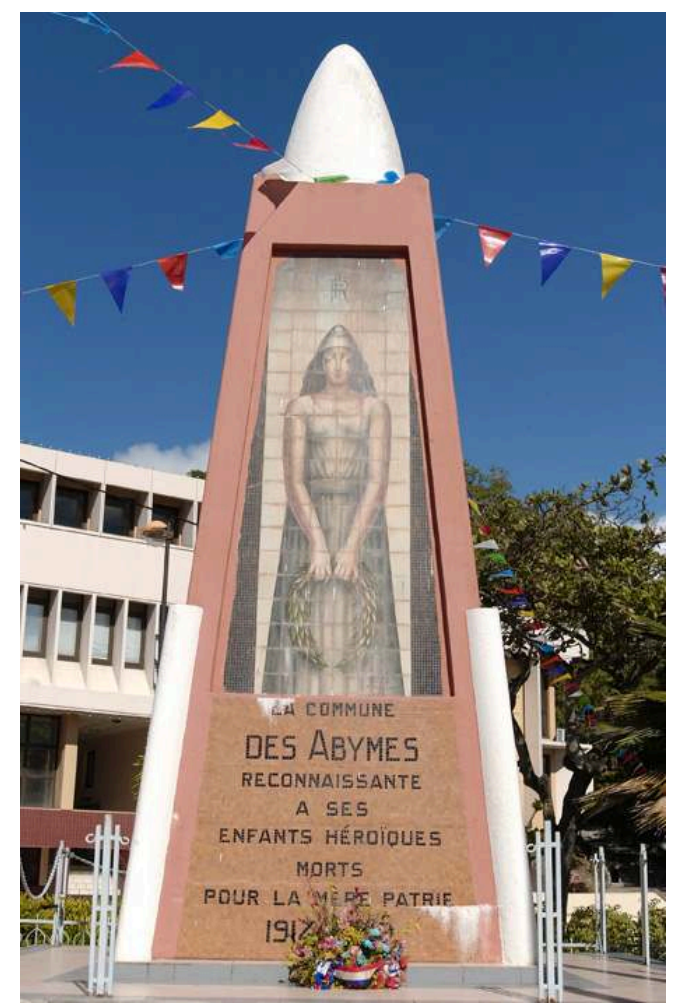

LES ABYMES, MONUMENT AUX MORTS, 1937.

Phot. Peiré, J.F., Inventaire général de Guadeloupe, 2002. (C) Inventaire général.

61 Le choix de son emplacement, sur une place, à l'articulation d'un ensemble urbain administratif de style moderniste réalisé par Ali Tur entre 1930 et 1933, et son style Art déco le rapprochent du monument aux morts du Lamentin. Cependant, la grande originalité de ce monument réside dans les panneaux de céramique peints qui ornent les quatre faces de l'obélisque.

Cet édifice est assez bien documenté, cependant on ignore comment s'est déroulé le recrutement de son auteur, Ardachès Baldjian, sculpteur et céramiste d'origine arménienne installé en Martinique depuis 1934. L'artiste a pu être repéré à l'exposition de 1935 au musée de la France d'outre-mer, à moins que la municipalité n'ait organisé, à l'instar de nombreuses communes métropolitaines, un concours pour la réalisation de son monument aux morts.

63 Il a fallu dix ans à la mairie des Abymes pour concrétiser ce projet et réunir les fonds nécessaires. Les moyens qu'elle y consacre sont d'ailleurs importants puisque le contrat signé entre la Ville et l'entrepreneur Payot-Kahn-Farcy ${ }^{44}$ révèle un coût de $136000 \mathrm{~F}$, répartis entre l'entrepreneur $(71000 \mathrm{~F})$ et l'artiste $(65000 \mathrm{~F})$, soit un montant près de $160 \%$ plus élevé que le monument aux morts de Baie-Mahault $(50000 \mathrm{~F})^{45}$ inauguré la même année. Ce même contrat indique encore que Baldjian s'est rendu en France pendant plusieurs mois pour l'exécution et la cuisson des carreaux de céramique et qu'il a ensuite dirigé leur assemblage et leur pose sur le monument en Guadeloupe.

L'inauguration a lieu le 26 décembre 1937, en présence du maire Max Clainville Bloncourt et du gouverneur Félix Éboué, en poste de 1936 à 1938 (fig. 22). On l'a vu, le gouverneur joue un rôle important en Guadeloupe et Éboué est donc l'interlocuteur de 
Baldjian, qui lui adresse un courrier le $1^{\mathrm{er}}$ décembre $1937^{46}$ dans lequel il donne des informations intéressantes sur le programme iconographique de son œuvre, en légendant les photos qui l'accompagnent (fig. 23).

\section{Figure 22}

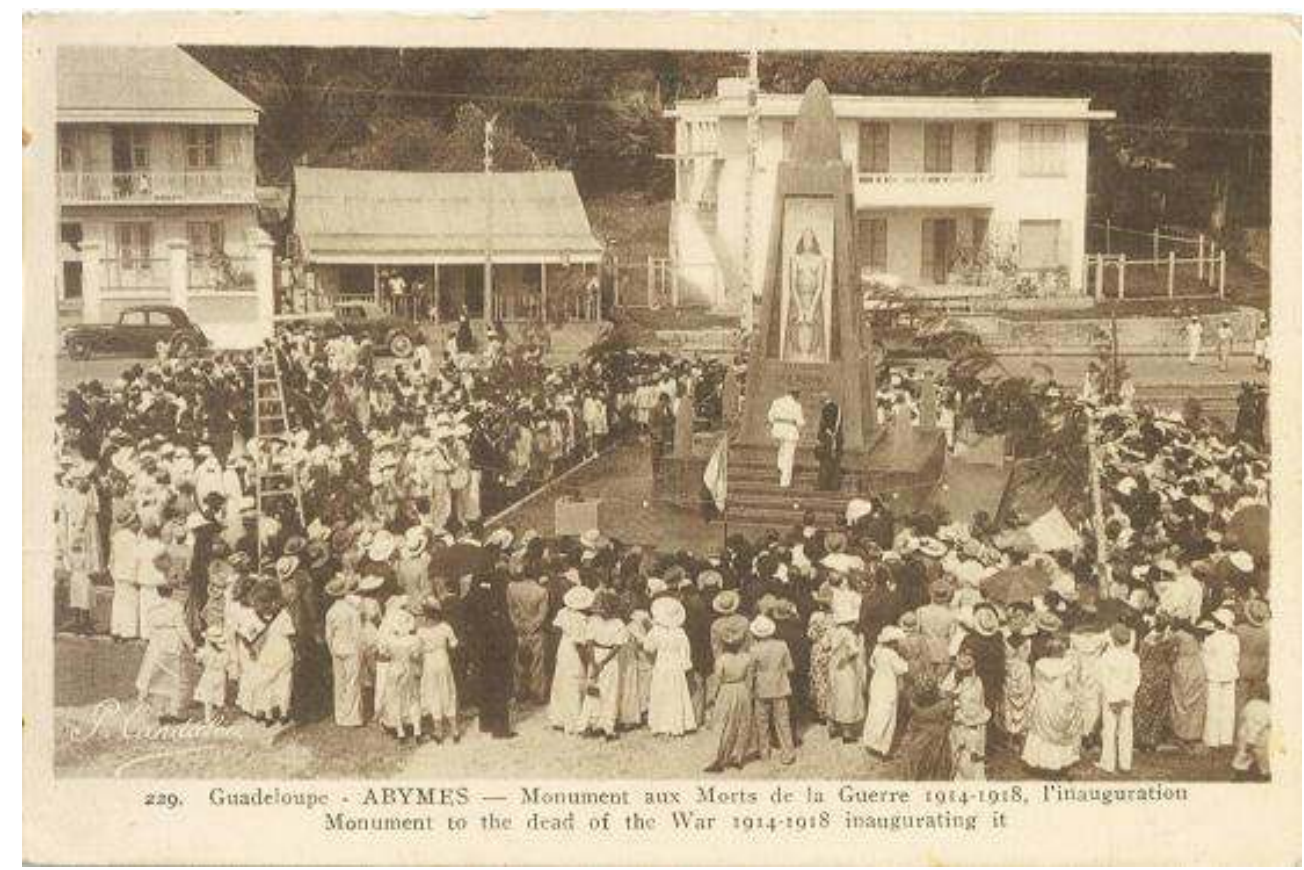

LES ABYMES, INAUgURATION DU MONUMENT AUX MORTS, 26 dÉCEMBRE 1937. CARTE POSTALE, ARCHIVES DÉPARTEMENTALES DE LA GUADELOUPE, 5 FI 5/87.

(C) Archives départementales de la Guadeloupe. 
Figure 23

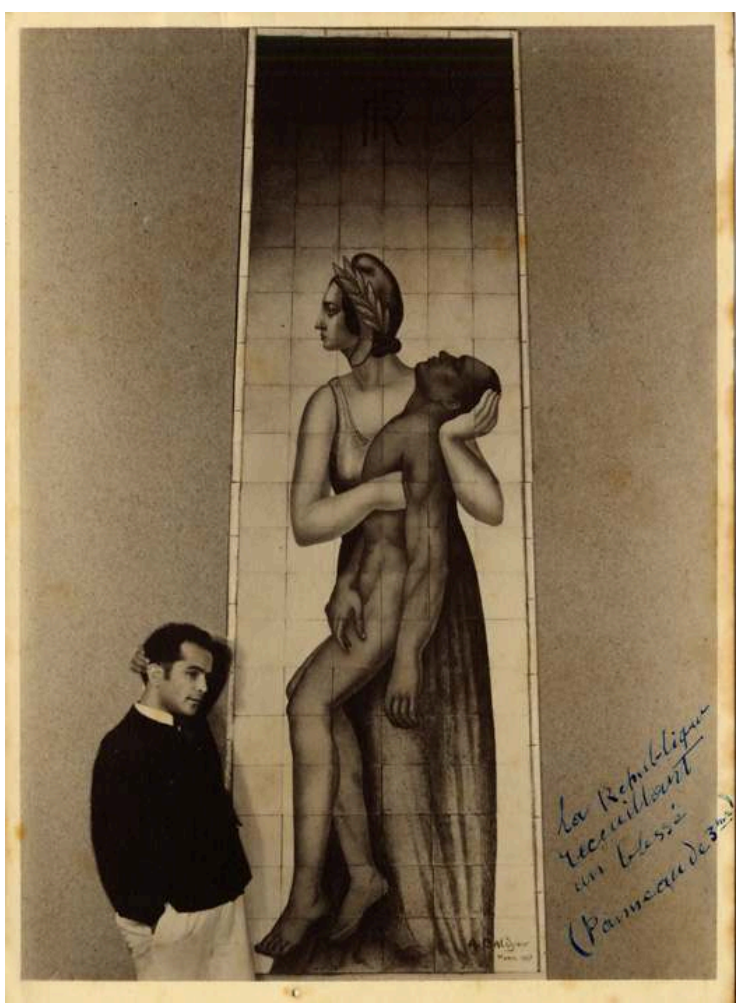

A. BALDJIAN POSANT À PARIS DEVANT LE PANNEAU DE LA RÉPUBLIQUE RECUEILLANT UN BLESSÉ. ARCHIVES DÉPARTEMENTALES DE LA GUADELOUPE, INC 152/1.

(C) Archives départementales de la Guadeloupe.

Félix Éboué parvient à apaiser un climat social très dégradé depuis la crise économique qui n'a cessé de s'aggraver depuis le passage du cyclone de 1928. Haut fonctionnaire noir originaire de Guyane, il est l'incarnation des succès promis par les tenants de la pensée assimilationniste. Il tente d'appliquer en Guadeloupe sa devise, "Légalité, Neutralité, Égalité ", de défendre les valeurs de tolérance et d'humanisme. Dans cette perspective, l'inauguration du monument aux morts des Abymes a donc été un moment de rassemblement et d'union républicaine, dans l'esprit du discours prononcé par Maurice Bourgeois, secrétaire général de l'Union des anciens combattants de la Guadeloupe, qui porte l'espoir d'un renouveau: «bannies à nos yeux les luttes fratricides, génératrices de misère et de ruines (...). Nous croyons fermement à une rénovation du genre humain, vivant désormais sous le signe de l'union dans la Paix ${ }^{47}$.

La première singularité du monument aux morts des Abymes réside dans la transformation de l'obélisque, symbole traditionnel des vainqueurs, en engin de guerre. Si l'obus a été assez couramment utilisé pour matérialiser une barrière autour du monument - comme c'était d'ailleurs le cas aux Abymes avant que les abords immédiats du monument ne subissent plusieurs transformations -, l'application de cette forme au monument lui-même est beaucoup plus exceptionnelle. Instrument de la guerre moderne et mondialisée, symbole de destruction massive, l'obus est ici cloué au sol et comme neutralisé. Il devient aussi, grâce au dessin de Baldjian, un élément décoratif résolument nouveau. Toutefois, la principale originalité du monument réside dans les quatre panneaux décoratifs qui ornent le fût et réinterrogent les sujets 
traditionnels du genre commémoratif en inventant une iconographie très contextualisée qui mérite d'être détaillée ici.

Le premier panneau, situé à peu près dans l'axe de l'ancienne mairie, s'intitule La République offrant une couronne à ses enfants (fig. 24). Une femme vue de face est habillée d'une robe à l'antique et porte un bonnet phrygien sur ses longs cheveux dénoués. Audessus d'elle, le monogramme RF aux lettres entremêlées symbolise l'appartenance de ce territoire ultramarin à la République française et son attachement aux valeurs de la République. La figure féminine tient devant elle, les bras le long du corps, une couronne de lauriers. Mais l'expression de l'allégorie n'est pas celle du triomphe. Dès le premier panneau, Baldjian montre sa sensibilité : sa République a les yeux fermés, elle est recueillie dans le souvenir des morts, sobrement repliée sur la douleur qu'elle partage avec ceux qui ont perdu leurs fils, leurs frères, leurs maris. La couronne des vainqueurs s'est remportée au prix des larmes et du sang, ce que représente de manière plus explicite et pathétique encore le très beau bas-relief du sculpteur Daniel Bacqué au monument aux morts de Vianne (Lot-et-Garonne, 1920) (fig. 25).

Figure 24

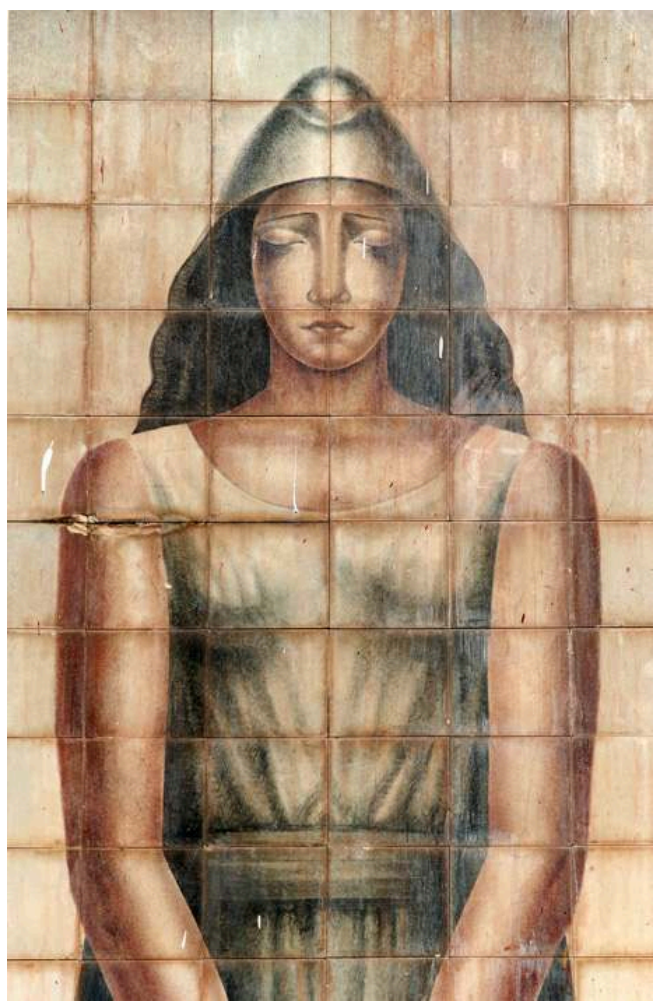

A. BALDJIAN, LA RÉPUBLIQUE OFFRANT UNE COURONNE À SES ENFANTS. DÉTAIL DU MONUMENT AUX MORTS DES ABYMES, 1937.

Phot. Peiré, J.F., Inventaire général de Guadeloupe, 2002. ㅇ Inventaire général. 
Figure 25

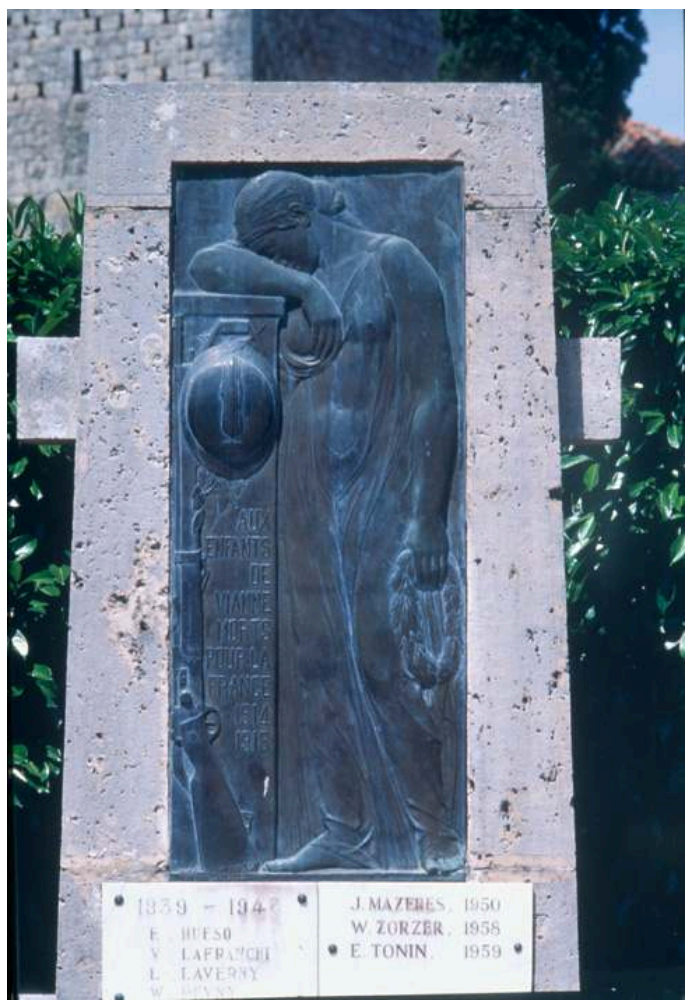

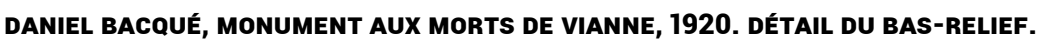

Phot. Dubau, Michel, Inventaire général, Région Aquitaine, 2000. (c) Inventaire général, Région Aquitaine.

Le panneau suivant, La Guadeloupe victorieuse (fig. 26), est dans le même esprit. La Victoire guadeloupéenne, incarnée par une femme noire coiffée à l'antillaise d'un simple foulard, n'est ni revancharde ni exaltée. Digne et recueillie, elle tient sa main droite contre son sein, fermée sur la palme du martyr. Deux messages de paix et d'espérance l'accompagnent: la croix latine et la colombe de la paix. Comme dans le précédent panneau, la composition est parfaitement frontale et la pureté du dessin est au service de la sobriété du discours et des émotions. 
Figure 26

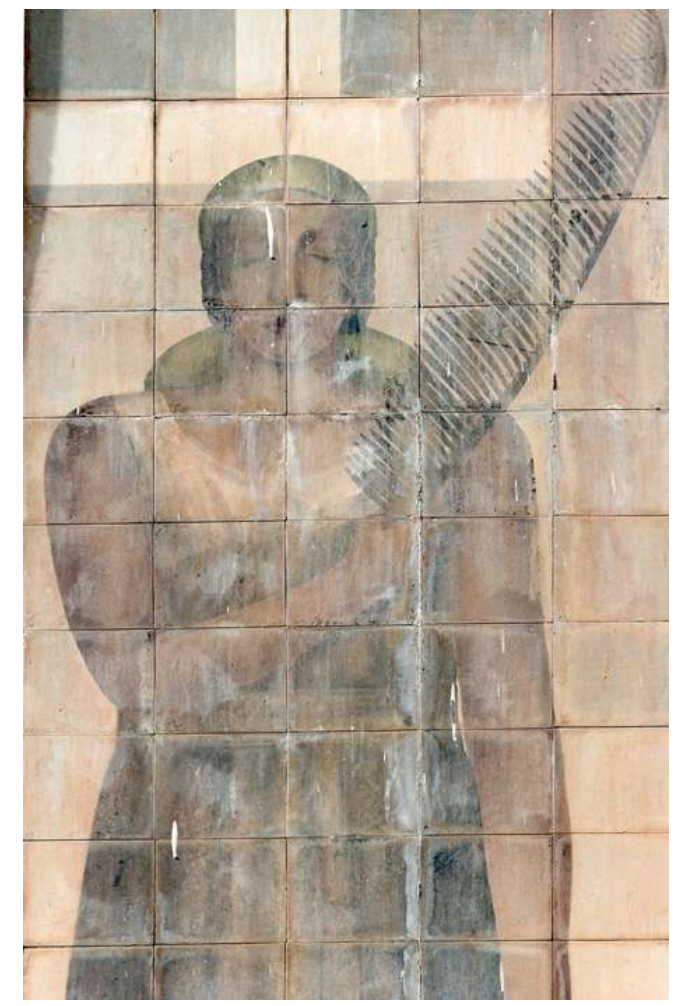

A. BALdJIAN, LA GUADELOUPE VICTORIEUSE. DÉtAIL dU MONUMENT AUX MORTS DeS ABYMES, 1937.

Phot. Laborie, S., 2013. (C) S. Laborie.

Le panneau de La République recueillant un blessé (fig. 27) est d'une grande force. La République est coiffée du bonnet phrygien et d'une couronne de lauriers. D'un geste maternel, elle porte, plus qu'elle ne soutient, le corps totalement nu et abandonné d'un homme noir, vu de profil, et dont rien ne rappelle la condition de soldat. Dans cette composition qui évoque celle d'une Piétà, l'artiste s'est attaché à rendre le souffle de l'homme expirant dans les bras protecteurs et maternels de la République. Cependant, l'attitude volontaire et combative de la République n'est pas l'affliction qui caractérise l'attitude de la Vierge dans les Piétà et que l'on observe sur les monuments aux morts de Saint-François ${ }^{48}$ (voir fig. 4) et de Pointe-à-Pitre (voir fig. 5). On peut mettre cette iconographie très rare en rapport avec un groupe sculpté de Joseph Ebstein (1881-1961) pour le monument aux morts de la Grande Guerre érigé en 1922 à Marengo en Algérie ${ }^{49}$ (fig. 28). 
Figure 27

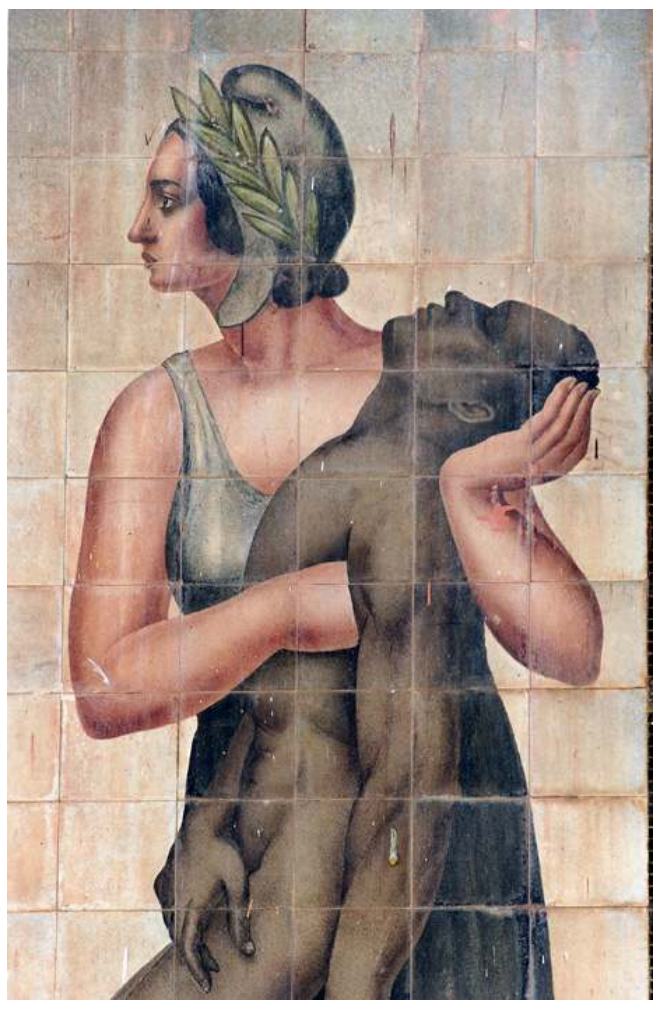

A. BALDJIAN, LA RÉPUBLIQUe RECUEILLANT UN BLESSÉ. DÉtAIL DU MONUMENT AUX MORTS DES ABYMES, 1937.

Phot. Peiré, J.F., Inventaire général de Guadeloupe, 2002. ( I Inventaire général. 
Figure 28

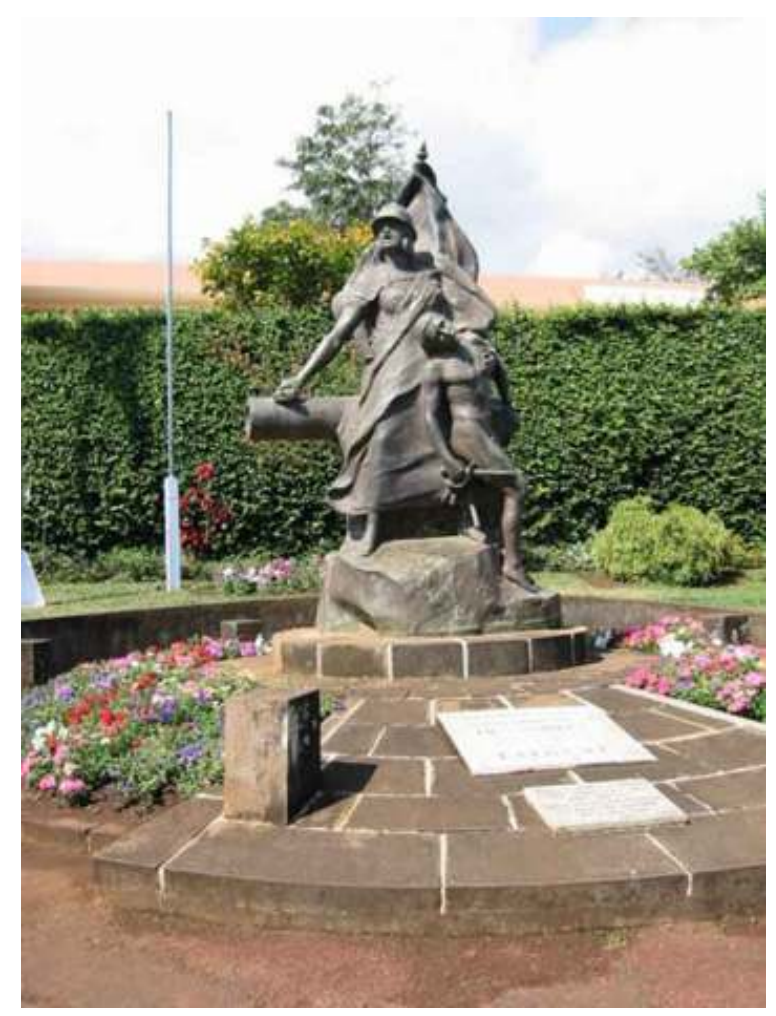

JOSEPH EBSTEIN, MONUMENT AUX MORTS DES AVIRONS, 1922 (ANCIENNEMENT MARENgO, ALgÉRIE). DÉTAIL.

Phot. Mairie des Avirons, île de la Réunion. (C) Mairie des Avirons.

Le dernier panneau est celui de La participation des troupes coloniales dans tous les corps d'armée (fig. 29). Cette face du monument est sans doute la plus originale des quatre. En effet, le poilu d'outre-mer (le POM) y est représenté par un homme noir, seulement vêtu d'un cache-sexe, vu de trois quarts face dans la même attitude dynamique que la République du panneau précédent. Sur son bras levé sont symbolisés tous les corps de l'armée française : l'avion, pour l'aéronautique militaire alors naissante ${ }^{50}$, l'armée de terre représentée par la cavalerie (le cheval), l'artillerie (le canon) et l'infanterie (le fusil). Ils symbolisent l'union victorieuse des forces dans le combat. L'ancre, en bas à droite de la composition, est celle de l'infanterie des troupes coloniales qui la porte depuis 1900 sur ses uniformes et que l'on trouve également sur le casque des soldats de Baie-Mahault et de Port-Louis. Outre le fait, déjà singulier, que ce soldat soit un Noir ${ }^{51}$, il est également nu. Cette nudité, si inhabituelle sur un monument de ce type, pose question. À l'opposé d'une allusion péjorative à une culture que certains qualifient encore à l'époque de "primitive ", nous y voyons une interprétation à l'antique d'un sujet héroïque. Ce «nu héroïque » est d'ailleurs en cohérence avec le traitement à l'antique des figures féminines, vêtues de longues robes fluides dégageant les épaules. 
Figure 29

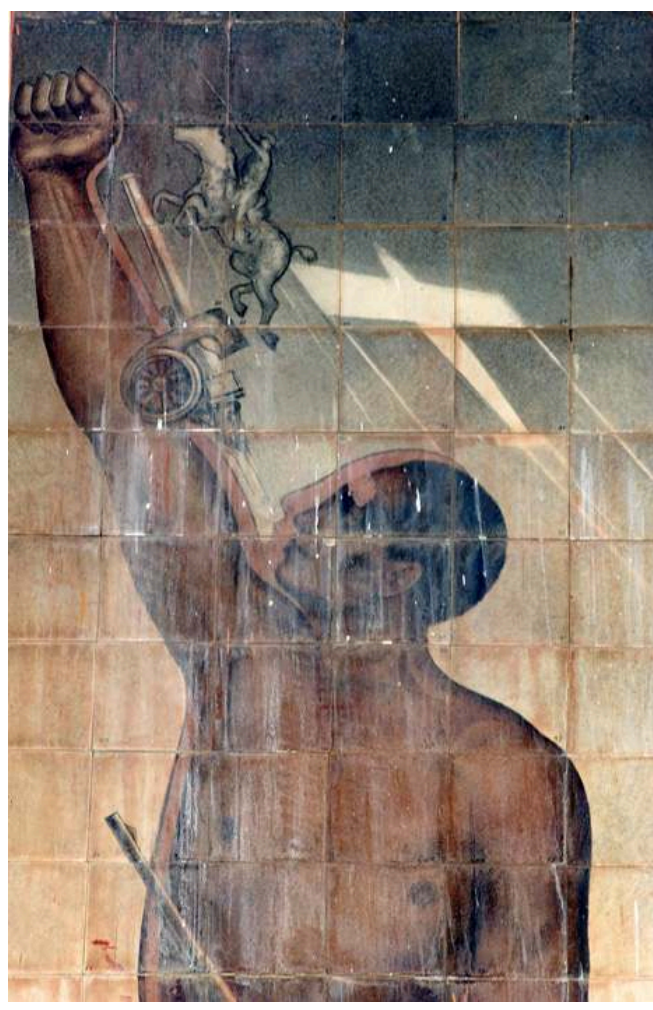

A. BALDJIAN, LA PARTICIPATION DES TROUPES COLONIALES DANS TOUS LES CORPS D'ARMÉE. DÉTAIL DU MONUMENT AUX MORTS DES ABYMES, 1937.

Phot. Laborie, S., 2013. (c) S. Laborie.

À ce programme iconographique original s'ajoute un traitement très moderne, pictural, du décor figuratif. La composition va à l'essentiel, vise la sobriété. Le dessin privilégie les formes rondes, les lignes épurées; le volume est rendu par des ombres simplifiées. Cette esthétique rapproche Baldjian du peintre Georges Rohner, de six ans son aîné, arrivé en Guadeloupe en 1934 pour effectuer son service militaire. Baldjian a une formation de sculpteur (il est passé par l'atelier d'Antoine Bourdelle) et de céramiste, mais en Martinique il se tourne vers la peinture. Il a pu entrer en contact directement avec Rohner ou avec ses œuvres en 1935 au musée de la France d'outre-mer à Paris, à l'occasion de l'exposition sur les Antilles françaises organisée dans le cadre des festivités du Tricentenaire. En Guadeloupe, il découvre le décor de la salle du conseil de l'hôtel de ville de Basse-Terre, peint par Rohner la même année ${ }^{52}$ (fig. 30). Comme lui, Baldjian se rattache au courant moderniste caractérisé par la stylisation des formes, l'économie de moyens et la place de l'homme dans l'espace. Il partage également avec le mouvement Forces nouvelles le goût pour les formes simples et le retour à une certaine tradition dans l'art. Pierre Cabanne livre une analyse des artistes de Forces nouvelles qui s'applique parfaitement à l'auteur des panneaux du monument aux morts des Abymes : "ces analystes du réel sont des «objéistes ", ils apprécient à leur juste mesure une forme, un volume, un poids dans l'espace, [...] ils donnent à la réalité un contenu spirituel fait de gravité, de recueillement, de ferveur $»^{53}$. Comme chez les membres du groupe Forces nouvelles inspirés par la grande exposition des Peintres de la réalité en France au XVII ${ }^{\mathrm{e}}$ siècle présentée au musée de l'Orangerie en 1934, Baldjian 
privilégie les teintes sourdes, une palette de gris, gris-bleu, gris-vert et brun et élimine tout détail anecdotique.

Figure 30

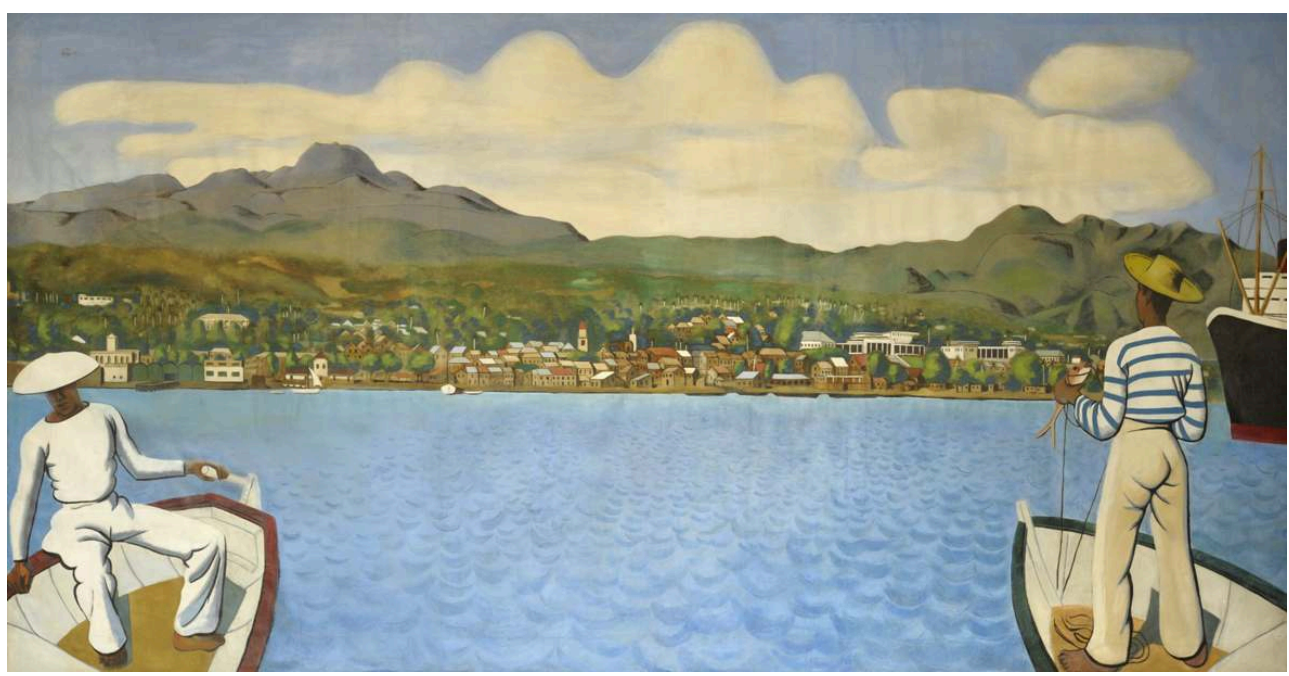

GEORgES ROHNER, LA RADE DE BASSE-TERRE, 1935. ÉLÉMENT DE DÉCOR DE L'HÔTEL DE VILLE DE BASSETERRE.

PHOT. VIRAPIN, PH. (C) PH. VIRAPIN.

Toutefois, l'histoire personnelle de Baldjian a pu jouer un rôle dans le traitement de ce sujet mémoriel. En effet, ce natif d'Arménie n'a que sept ans en 1917 lorsque les Turcs massacrent le peuple arménien. Il échappe au génocide par miracle, sauvé par un paysan, mais assiste à des scènes d'une cruauté infinie, voit sa propre mère décapitée sous ses yeux ${ }^{54}$. Ce drame n'a pas entravé sa vocation artistique, au contraire. Grandi dans des orphelinats en Grèce et en Italie, il arrive en France pour étudier la sculpture auprès d'Antoine Bourdelle. Son art est un moyen d'exorciser ce traumatisme avec lequel il doit vivre et, comme le souligne l'écrivain martiniquais Auguste Joyau, ses œuvres les plus représentatives «ont été conçues sous le signe de la souffrance. Non pas de cette souffrance amère qui suscite la haine et inspire la vengeance, mais de celle, profondément pitoyable, qui porte en soi le pardon et appelle la miséricorde $»^{55}$. 
Figure 31

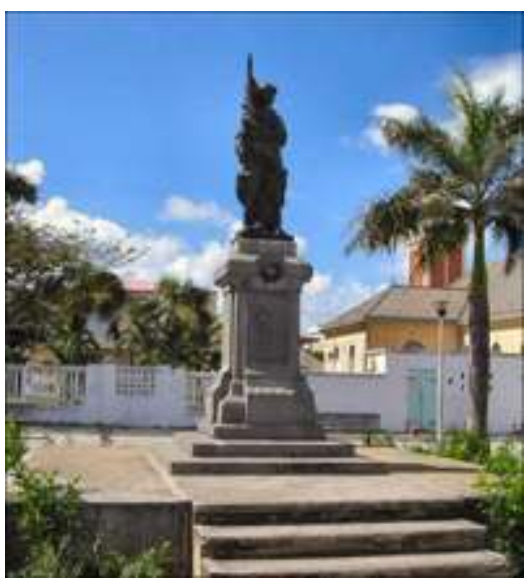

LE MOULE, MONUMENT AUX MORTS.

PHOT. LAUDET, BERNARD, 2004. (C) BERNARD LAUDET.

La puissance de l'œuvre de Baldjian et sa cohérence avec l'espace urbain environnant fondent l'exemplarité du monument aux morts des Abymes. Parmi les rares monuments édifiés après celui-ci, les Poilus du Moule (1938) (fig. 31) - fourni par le représentant local du marbrier Édouard Rombaud-Rolland - et de Morne-à-l'Eau (1939) (fig. 32) paraissent assez démodés. Après la Seconde Guerre mondiale, quelques monuments seront encore édifiés, mais seul celui de Sainte-Anne (1949) (fig. 33), œuvre du sculpteur Gilbert Privat également auteur du monument à Victor Schœlcher situé à proximité, renoue avec une certaine force d'interprétation, tout en demeurant fidèle au style Art déco un peu passé. 
Figure 32

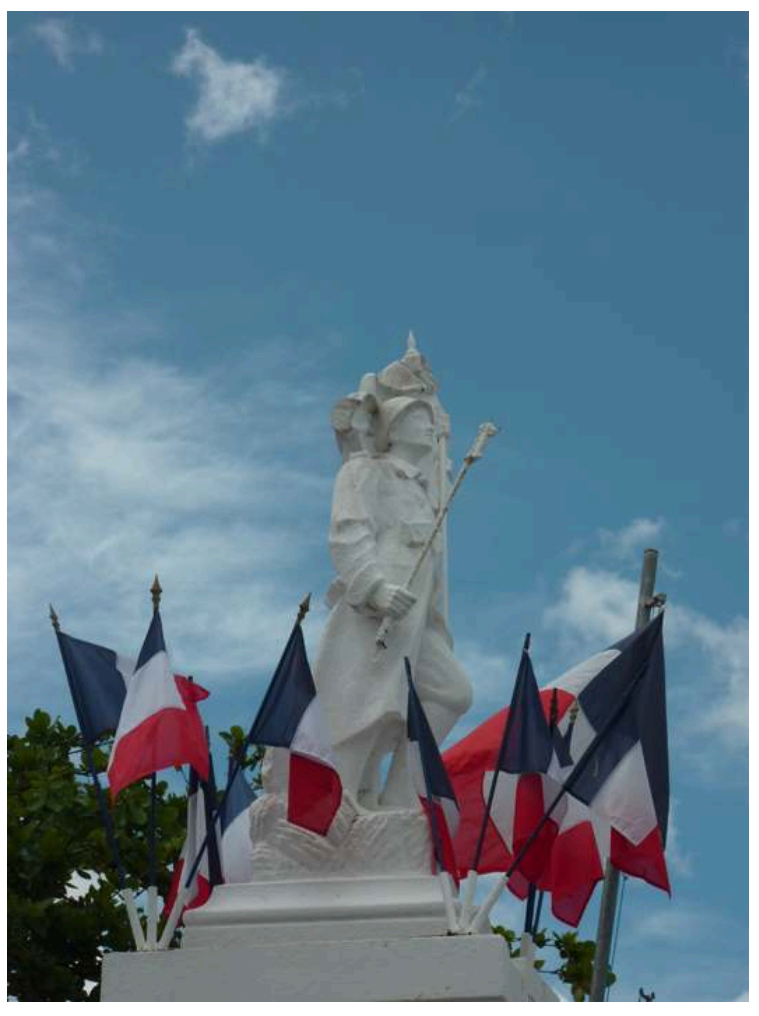

MORNE-À-L'EAU, MONUMENT AUX MORTS.

Phot. Laborie, S., 2014. (C) S. Laborie. 
Figure 33

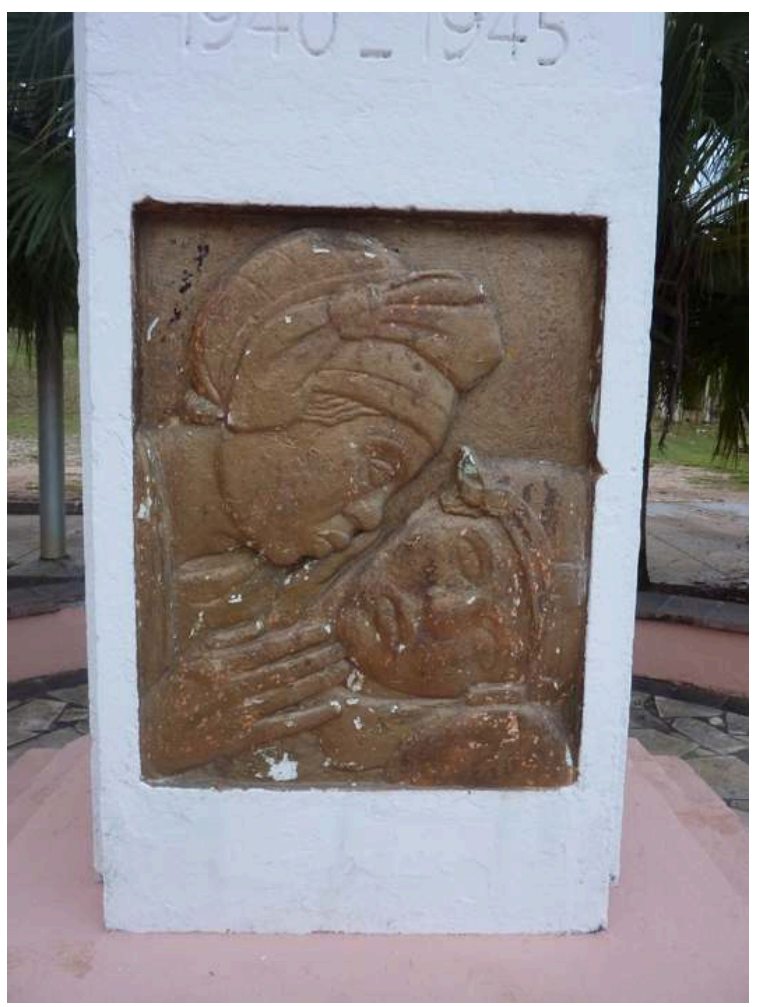

SAINTE-ANNE, MONUMENT AUX MORTS, 1949. DÉTAIL.

Phot. Laborie, S., 2013. (c) S. Laborie.

\section{Conclusion}

Cet inventaire des différents monuments aux morts de Guadeloupe confirme l'importance de la commémoration de la Grande Guerre dans l'archipel. Non seulement la quasi-totalité des communes ont fait édifier un monument à la mémoire des soldats morts pour la France, mais elles ont de surcroît surmonté des difficultés financières importantes pour faire l'acquisition d'œuvres, souvent produites en série mais pas seulement, les faire livrer et remonter sur place. Ces monuments commémoratifs constituent, dans leurs ressemblances et parfois leur uniformité, un trait d'union entre les différents peuples de France. Dans de rares cas, ils apparaissent comme « régionalisés »: parfois grossièrement, par une simple couche de peinture, parfois grâce à la création originale d'un artiste. En Guadeloupe, si tous ces cénotaphes portent à différents degrés d'expression l'exaltation des vertus républicaines et patriotiques, le sens de leur engagement demeure assez neutre: ni franchement pacifistes, ni franchement belliqueux, ils placent l'homme au centre du souvenir. Le soldat y apparaît souvent seul, en gardien de la mémoire des morts, de ceux dont les noms sont gravés dans la pierre et dont les corps sont restés « là-bas » et sont parfois tombés dans l'oubli.

De nos jours souvent ignorés, ou objets de dégradations volontaires, ils sont surtout méconnus. Dans le paysage antillais, ils acquièrent même une certaine incongruité : qu'est-ce qu'évoque aujourd'hui ce soldat blanc, chaudement sanglé dans son costume d'un autre siècle, fusil et drapeau national en main ? Les commémorations nationales 
du 11 novembre et du 8 mai ne réunissent plus grand monde, même si la tradition perdure. Ainsi, il apparaît nécessaire d'accompagner la mise en place de mesures de protection, d'actions de médiation. Les commémorations du Centenaire de la Grande Guerre sont l'occasion de s'interroger sur cette mémoire et sur ces symboles et au-delà, sur la complexité et la force des liens entretenus par la France avec ses anciennes colonies des Antilles. Il convient de leur redonner leur place en tant que témoins historiques, qu'il s'agisse de l'histoire politique, de l'histoire des mentalités, de l'histoire de l'art, de l'histoire des communes et de celle des familles.

\section{NOTES}

1. - Derniers chiffres communiqués par Anne Lebel, directrice des Archives départementales de la Guadeloupe, lors de sa communication «De la difficulté de compter les soldats guadeloupéens morts pour la France pendant la première guerre mondiale ", colloque La Caraibe et la Première Guerre mondiale, 19 et 20 mai 2014, Basse-Terre. Actes à paraître.

2. - ERBS, Philippe. Les Monuments aux morts de la guerre 1914-1918 de la Guadeloupe. Mémoire de maîtrise d'histoire dirigé par Danielle Bégot, Université Antilles-Guyane, 2003. Archives départementales de la Guadeloupe, cote 22J6.

3. - À la veille de la guerre la France hexagonale compte 39,5 millions d'habitants quand son empire colonial en compte environ 100 millions. La population de la Guadeloupe est estimée à 220000 habitants.

4. - Le 4 avril 1792, l'Assemblée nationale décide d'accorder la pleine citoyenneté à tous les libres de couleur. La Convention abolit l'esclavage par le décret du 4 février 1794. Cependant, seules trois colonies ont bénéficié de cette mesure : Saint-Domingue, la Guadeloupe - reconquise par le républicain Victor Hugues qui proclame l'abolition le 7 juin 1794 - et la Guyane française. En effet, les Anglais s'emparent de la Martinique en mars 1794 avec l'appui des colons autonomistes qui refusent l'abolition, et ne la rendent aux Français, avec Sainte-Lucie et Tobago, qu'à l'issue de la Paix d'Amiens en 1802.

5. - Le colonel Delgrès, à la tête des rebelles, est vaincu par le général Richepanse, envoyé par Bonaparte pour rétablir l'esclavage.

6. - Sur ces questions, se référer à DORIGNY, M. et GAINOT, B. Atlas des esclavages : traites, sociétés coloniales, abolitions de l'Antiquité à nos jours. Paris : Editions Autrement, 2006.

7. - Des députés antillais élus au suffrage universel siègent désormais à l'Assemblée nationale, tandis que les conseils coloniaux sont supprimés; les conseils municipaux, créés en 1837, sont réorganisés sur la base du suffrage universel.

8. - Lettre de Victor Schœlcher adressée aux électeurs de la Guadeloupe et de la Martinique après qu'il ait été élu député de la Martinique, rédigée à Paris le 29 septembre 1848.

9. - La loi du 15 juillet 1889 établit plus d'égalité dans la durée du service actif qui est réduit à trois ans. Elle supprime les exemptions pour les ecclésiastiques et les enseignants qui sont désormais tenus à un an de service. Les bons numéros au tirage au sort et les hommes faisant valoir un bon motif de dispense ne font qu'un an. La loi du service militaire du 21 mars 1905 établit le service universel et égalitaire pour tous, d'une durée de deux ans. Elle autorise les originaires des Antilles et de la Guyane à s'engager volontairement dans l'armée coloniale (art. 37). 
10. - Le Nouvelliste de la Guadeloupe, 4 mars 1913. Cité par BROUSSILLON, Ary. La Guadeloupe dans la Première Guerre mondiale. Gourbeyre : Les éditions Nestor, 2008, p. 28.

11. - Musée fondé en 1887 à partir du don de Victor Schœlcher à la Guadeloupe d'une partie de ses collections.

12. - Cité par BROUSSILLON, A., op. cit., p. 37.

13. - Les Guadeloupéens sont ainsi débarqués dans les lazarets des Saintes et de l'îlet à Cosson.

14. - Une circulaire du ministre de la Guerre datée du 12 avril 1915 précise qu'à leur arrivée les soldats créoles sont envoyés dans des dépôts d'infanterie coloniale pour y être formés et que les réservistes sont affectés au dépôt d'infanterie métropolitaine. Tous doivent poursuivre leur instruction, même ceux qui l'ont déjà effectuée ou commencée avant leur départ.

15. - Pierre Belain d'Esnambuc (1585-1636), navigateur d'origine normande, pratique la piraterie artisanale lorsqu'il s'installe en 1623 sur l'île de Saint-Christophe. Deux ans plus tard, Richelieu lui accorde le privilège de coloniser la Martinique, la Guadeloupe et ses dépendances, marquant ainsi le début de l'histoire coloniale de la France. En 1635 est fondée la Compagnie des îles d'Amérique. Le comité métropolitain du Tricentenaire est présidé par Henry Bérenger, sénateur de la Guadeloupe.

16. - Dans toute la France, ce sont 440 monuments à la gloire de la République qui sont édifiés entre 1870 et 1940. Voir AGULHON, M. et BONTE, P. Marianne. Les visages de la République. Paris : Gallimard, 1992.

17. - La volonté de renforcer des liens avec la métropole est très forte. Elle s'exprime d'une manière particulièrement intéressante dans l'«adoption » du village de Neuvilly-en-Argonne (Meuse). La Guadeloupe participe financièrement à la reconstruction de ce village martyr de la guerre et lève une souscription qui permet l'édification de son monument aux morts en 1926.

18. - ERBS, P., op. cit., p. 33.

19. - ERBS, P., op. cit., p. 48.

20. - Voir KACY, Franck. « Expression du patriotisme colonial à Marie-Galante en 1919, l'érection du premier monument aux morts de la Guadeloupe ». Dans Commémorer et dénoncer la guerre. Actes $\mathrm{du} 136^{\mathrm{e}}$ Congrès national des sociétés historiques et scientifiques, Perpignan, 2011. Document électronique, CTHS.

21. - ERBS, P., op. cit., p. 70.

22. - Le groupe sculpté représente la Nation éplorée tenant dans ses bras un poilu mort. Il semble très proche de celui du monument aux morts de Valentigney (Doubs), réalisé en 1920 par le sculpteur Henri Valette (1877-1962).

23. - ERBS, P., op. cit., p. 159-160.

24. - Hippolyte-Marius Galy est né à Alger. Élève de Dumont et de Cormon. Sociétaire des Artistes Français depuis 1891, il figura au Salon de cette société et obtint une mention honorable en 1898.

25. - ERBS, P., op. cit., p. 70.

26. - $\mathrm{N}^{\circ} 3548 \mathrm{du}$ catalogue.

27. - $\mathrm{N}^{\circ} 3313$ du catalogue. Voir MAINGON, Claire. «L'après-Grande Guerre, entre patriotisme et revanche. Les monuments commémoratifs au Salon des artistes Français ». Dans La guerre après la guerre. Images et construction des imaginaires de guerre dans l'Europe $\mathrm{du} \mathrm{XX}^{e}$ siècle, collection Histoire culturelle. Paris : Editions Nouveau Monde, 2010, p. 27-47.

28. - Le monument de Guingamp est inauguré le 11 novembre 1924.

29. - Le monument est arrivé en pièces détachées par bateau. Il a été remonté pièce par pièce par un artisan de Basse-Terre, M. Charlery. Voir ERBS, P., op. cit., p. 90-91, et brochure « Un artisan de Basse-Terre et le monument aux morts ", Archives municipales de Basse-Terre.

30. - ERBS, P., op. cit., p. 70.

31. - Fonderies et ateliers de construction du Val d'Osne. Fascicule commémoratif, 1921. La société a son siège 58, bd Voltaire, à Paris. 
32. - L'exemple le plus connu est sans doute celui du Poilu victorieux d'Eugène Benet, dont le tirage par les ateliers de la fonderie Antoine Durenne est estimé à plus de 900 exemplaires.

33. - ERBS, P., op. cit., p. 70.

34. - $\mathrm{N}^{\circ} 2152$ du catalogue. Les Marbreries Générales sont alors dirigées par Georges Gourdon.

35. - Comme au Crotoy (Somme) en 1920, à Juziers (Yvelines) en 1921, à Tournon d'Agenais (Lotet-Garonne) en 1922, à Lezay (Deux-Sèvres), etc.

36. - BECKER, Annette. Les monuments aux morts : patrimoine et mémoire de la Grande Guerre. Paris : Errance, 1988.

37. - ERBS, P., op. cit., p. 70.

38. - Les monuments composites proposés dans leur catalogue par les Marbreries générales déclinent en diverses combinaisons des motifs récurrents. Ainsi, la Victoire est associée, dans la référence $n^{\circ} 2129$ à un Poilu combattant, tels qu'on pouvait les observer sur le monument aux morts de Saint-Méloir-des-Ondes (Ille-et-Vilaine, disparu).

39. - ERBS, P., op. cit., p. 71.

40. - N²027 du catalogue des Marbreries Générales.

41. - Le poilu a été peint en noir.

42. - Communication orale de Pascale Forestier, Archives départementales de la Guadeloupe.

43. - Suite à cette récompense, Louis Bate part en Indochine et obtient un poste d'enseignant à l'école d'architecture de Dalat, où il trouve la mort dans des circonstances violentes. Voir THORNTON, Lynne. Les Africanistes, peintres voyageurs : 1860-1960. Paris: ACR Editions, 1990, p. $168-170$.

44. - Ce document est conservé chez un particulier à Petit-Bourg.

45. - ERBS, P., op. cit., p. 58.

46. - Lettre de Baldjian du $1^{\text {er }}$ décembre 1937 au gouverneur Félix Eboué. Archives départementales de la Guadeloupe, fonds de l'incendie, cote provisoire INC 152 / 1.

47. - Le Nouvelliste de la Guadeloupe, 29 décembre 1937.

48. - ERBS, P., op. cit., p. 70.

49. - Joseph Ebstein (1881-1961), sculpteur et graveur français natif de Batna en Algérie, a réalisé plusieurs monuments aux morts en Algérie. À l'exception de celui de Constantine encore en place, les autres ont été déplacés après l'indépendance. Le monument aux morts de Marengo a été déplacé en 1965 à l'initiative d'André Malraux, alors ministre de la Culture, qui l'a offert à la commune des Avirons sur l'île de la Réunion.

50. - L'armée de l'air ne se constitue en tant que telle qu'en 1934.

51. - Sur la période étudiée, seuls deux monuments aux morts de Guadeloupe représentent des soldats noirs : à Baie-Mahault et aux Abymes. Le Poilu d'outre-mer du monument de Port-Louis n'est pas caractéristique. En dehors du cadre chronologique de cette étude, en 1949, le bas-relief $\mathrm{du}$ monument aux morts de Sainte-Anne montre le visage d'un soldat noir.

52. - Georges Rohner et la Guadeloupe, 1934-1936. Pointe-à-Pitre: Jasor, 2011. Catalogue de l'exposition, Paris, musée de la Marine 19 oct. 2011-16 janvier 2012 et Basse-Terre, L'Artchipel, 2 mars - 5 mai 2012.

53. - CABANNE, Pierre. Georges Rohner. Neuchâtel : Ides et Calendes. Paris : La bibliothèque des arts, 1971, p. 54.

54. - L'ETANG, Gerry (dir.). La Peinture en Martinique. Paris : HC Editions, 2007, p. 70-72.

55. - Rétrospective Ardachès Baldjian. Bibliothèque Schœlcher, 13 mai-12 juin 1989. 


\section{ABSTRACTS}

The four 'old' French colonies of Guadeloupe, Martinique, French Guiana and Reunion all participated in the French military engagement during the First World War. For Guadeloupe, it has been estimated that 9,151 men were called up, 6,345 of whom were sent to fight in the European theatre. In order to honour the memory of the 1,168 Guadeloupe soldiers who died 'for France', commemorative monuments were erected after the end of the war in many of the archipelago's communes, whatever their size, following the pattern set in mainland France.

Les quatre «vieilles » colonies que sont la Guadeloupe, la Martinique, la Guyane et la Réunion, ont participé à l'engagement militaire français pendant la Première Guerre mondiale. Pour la Guadeloupe, on estime que ce sont 9151 conscrits qui sont mobilisés, parmi lesquels 6345 sont envoyés sur les fronts européens. Afin d'honorer la mémoire des 1168 soldats guadeloupéens "morts pour la France », des monuments commémoratifs sont édifiés dès le lendemain de la guerre dans les communes de l'archipel, quelle que soit leur taille, à l'instar de la métropole.

\section{INDEX}

Mots-clés: monument aux morts, Guadeloupe, Martinique, guerre 14-18, empire colonial français, esclavage, Victor Schœlcher, commémoration, Poilus

\section{AUTHOR}

\section{SÉVERINE LABORIE}

Chargée d'études documentaires, direction des Affaires culturelles de Guadeloupe severine.laborie@culture.gouv.fr 